\title{
LLECMOD: A Bivariate Population Balance Simulation Tool for Liquid- Liquid Extraction Columns
}

\author{
Menwer M. Attarakih ${ }^{\mathrm{a}, \mathrm{c}}$, Hans-Jörg Bart ${ }^{*, a}$, Tilmann Steinmetz ${ }^{\mathrm{a}}$, Markus Dietzen ${ }^{\mathrm{a}}$ and \\ Naim M. Faqir ${ }^{b}$
}

\begin{abstract}
${ }^{a}$ University of Kaiserslautern, Faculty of Mechanical \& Process Engineering, Thermische Verfahrenstechnik, P.O.B. 3049, 67653 Kaiserslautern, Germany

${ }^{b}$ University of Jordan, Faculty of Engineering \& Technology, Chemical Engineering. Department, 11942 Amman, Jordan

${ }^{c}$ Al-Balqa' Applied University, Faculty of Engineering \&Technology, Chemical Engineering Department, P.O.B. 15008, 1134-Amman, Jordan
\end{abstract}

\begin{abstract}
The population balance equation finds many applications in modelling poly-dispersed systems arising in many engineering applications such as aerosols dynamics, crystallization, precipitation, granulation, liquid-liquid, gas-liquid, combustion processes and microbial systems. The population balance lays down a modern approach for modelling the complex discrete behaviour of such systems. Due to the industrial importance of liquid-liquid extraction columns for the separation of many chemicals that are not amenable for separation by distillation, a Windows based program called LLECMOD is developed. Due to the multivariate nature of the population of droplets in liquid -liquid extraction columns (with respect to size and solute concentration), a spatially distributed population balance equation is developed. The basis of LLECMOD depends on modern numerical algorithms that couples the computational fluid dynamics and population balances. To avoid the solution of the momentum balance equations (for the continuous and discrete phases), experimental correlations are used for the estimation of the turbulent energy dissipation and the slip velocities of the moving droplets along with interaction frequencies of breakage and coalescence. The design of LLECMOD is flexible in such a way that allows the user to define droplet terminal velocity, energy dissipation, axial dispersion, breakage and coalescence frequencies and the other internal geometrical details of the column. The user input dialog makes the LLECMOD a user-friendly program that enables the user to select the simulation parameters and functions easily. The program is reinforced by a parameter estimation package for the droplet coalescence models. The scale-up and simulation of agitated extraction columns based on the populations balanced model leads to the main application of the simulation tool.
\end{abstract}

\section{INTRODUCTION}

In liquid-liquid contacting equipment such as completely mixed and differential contactors $[1,2]$, droplet population balance based-modeling is now being used to describe the complex interaction of hydrodynamics and mass transfer. This is due to the complex nature of the macroscopic dispersed phase interactions in a continuously turbulent flow field. These macroscopic interactions such as droplet breakage and coalescence result in a distributed population of droplets. This population is distributed not only in the spatial domain of the contacting equipment, but also randomly distributed with respect to the droplet state (properties) such as size, concentration and age. Within this framework it appears that Hulburt and Katz [3] and Valentas and Amundson [4] were among the first who introduced the population balance equation (PBE) into the modelling of chemical engineering processes involving dispersed phase operations. Such processes include unit operations carried out in batch and continuous stirred tanks as well as in differential contacting equipment such as crystallization [5,6], bubble [7] and liquid-liquid extraction columns (LLEC) [8-10]. In such unit

*Address correspondence to this author at the University of Kaiserslautern, Faculty of Mechanical \& Process Engineering, Thermische Verfahrenstechnik, P.O.B. 3049, 67653 Kaiserslautern, Germany;

E-mail: bart@mv.uni-kl.de operation equipment the dynamically changing behaviour of the dispersed particles, or strictly speaking droplets (or bubbles), makes it necessary to consider a detailed mathematical rather than lumped modelling approach. These details are necessary to describe the discontinuous events occurring due to the interaction of the turbulent continuous and the dispersed phases constituents (droplets) such as breakage and coalescence. Loosely speaking, the term breakage considers the interaction of a single droplet with the turbulent continuous phase where the droplet undergoes breakage if the turbulent kinetic energy transmitted to the droplet exceeds its surface energy [11]. On the other hand, droplet coalescence is expected to occur due to the interaction between two droplets and the turbulent continuous phase. The coalescence between these two droplets is considered to occur if the intervening liquid film has sufficient contact time to be drained out [12]. Consequently, it is expected to find a droplet size distribution along the spatial coordinate of the liquid-liquid contacting equipment. The strong simplification when assuming uniform droplet size distribution based on a mean droplet diameter $\left(d_{32}\right)$ is then obsolete [13-15]. Accordingly, the promising modelling of these phenomena, based on the population balances, offers not only the dispersed phase hold-up (volume concentration) but also any integral property associated with the resulting particle (droplet) distribution such as the mean droplet size and the specific inter- 
facial area required for the calculation of mass and heat fluxes [16-20].

The population balance approach is applied for modelling the behaviour of the interacting liquid-liquid dispersions in either two basic ways: the stage-wise and the differential models. In the stage-wise $[15,17,21,22]$ the multistage column is represented by a sequence of interacting stirred tanks with forward and backward flow components to compensate for the non-ideal behaviour of each tank. Practical examples of such columns are the perforated plate column, pulsed sieve plate column, Scheibel column and mixer and settler cascades. In this way, a population balance equation has to be written for each tank with the required boundary conditions. In the differential model approach the phases are continuously contacted and allowed to separate only at the exit from the contactor such as the spray column, the rotating disc contactor (RDC), pulsating plate, Kühni and the Oldshue-Rushton column. In such equipment, the PBE is usually formulated as a conservation law in terms of volume concentration (mass for constant dispersed phase density) $[8,9,16,20,23,24]$. The resulting differential model takes into account the droplet transport; breakage and coalescence as well as the necessary boundary conditions, though the latter are not clearly stated in the published literature. For a comprehensive review of mathematical modelling of liquidliquid extraction columns, their advantages and disadvantages, the interested reader could refer to Mohanty [25].

Concerning commercial simulation modules for liquidliquid extraction columns, a lot of software systems for modeling of chemical separation processes (such as distillation, absorption, extraction etc.) have been created to perform flowsheet based simulations. However, to the best of the authors' knowledge, there is no unique program available for the simulation of liquid-liquid extraction columns based on the bivariate spatially distributed population balance equations in the existing commercial software such as ASPEN, CHEMSEP, CEMCAD and so on. For example, ASPEN has ColSim which is an advanced stage-wise program for the simulation of industrial rotating disc contactors (RDCs), where it provides insights into column performance by using physically realistic and validated models for drop break-up and mass transfer. The models in ChemSep include the only available rate-based model for liquid-liquid extraction without population balance framework. Thus, there is a need to build a stand-alone windows based program that describes the steady state as well as the dynamic behavior of such extremely important separation equipment. The LLECMOD (Liquid-Liquid Extraction Column MODule) comes to fill this gap in process simulation and allows the description of the bivariate properties of the droplet swarm and the continuous phase (solute concentrations and droplet population distribution).

The basic feature of LLECMOD program is to provide the simulation of both transient and steady state through an interactive Windows input dialogs as well as a parameter estimation package for droplet coalescence models based on small scale laboratory devices. The LLECMOD is not restricted to a certain type of liquid-liquid extraction columns because it is built in the most general form, which allows the user to input the various droplet interaction correlations through a user defined functions. These functions include droplet terminal velocity taking into account the swarm effect, slowing factor due to column geometry, the breakage frequency and daughter droplet distribution, the coalescence frequency and the axial dispersion coefficients. LLECMOD is not restricted to any chemical systems since variable input functions based on the EFCE correlation types and/or IKcape functionality is provided.

Sample problems on the basis of the performance and the mass transfer of RDC and Kühni extraction columns are successfully simulated and compared to the experimental data $[26,27]$. However, other column types can easily be treated (e.g. packed and sieve tray columns, pulsed or spray columns) when using adapted correlations [2]. Accordingly, the applications of population balance simulation for column scale-up leading to optimal column design and optimization of operating conditions is now made possible within the LLECMOD environment.

\section{THE MATHEMATICAL MODEL}

\section{The SDPBE}

The general spatially distributed population balance EQUATION (SDPBE) describing the coupled hydrodynamics and mass transfer in LLECs in a one spatial domain could be written as $[19,20,28-31]$ :

$$
\begin{aligned}
& \frac{\partial f_{d, c_{y}}(\psi)}{\partial t}+\frac{\partial\left[u_{y} f_{d, c_{y}}(\psi)\right]}{\partial z}+\frac{\partial\left[\dot{c}_{y} f_{d, c_{y}}(\psi)\right]}{\partial c_{y}}= \\
& \frac{\partial}{\partial z}\left[D_{y} \frac{f_{d, c_{y}}(\psi)}{\partial z}\right]+\frac{Q_{y}^{i n}}{A_{c}} f_{y}^{i n}\left(d, c_{y} ; t\right) \delta\left(z-z_{y}\right)+\Upsilon\{\psi\}
\end{aligned}
$$

In this equation the components of the vector $\psi=\left[\begin{array}{llll}d & c_{y} & z & t\end{array}\right]$ are those for the droplet internal coordinates (diameter and solute concentration), the external coordinate (column height), $z$, and the time, $t$, where the velocity along the concentration coordinate $\left(c_{y}\right)$ is $\dot{c}_{y}$. The source term $r . \partial \zeta$ represents the net number of droplets produced by breakage and coalescence per unit volume and unit time in the coordinates range $[\zeta, \zeta+\partial \zeta]$. The left hand side is the continuity operator in both the external and internal coordinates, while the first part on the right hand side is the droplets axial dispersion characterized by the dispersion coefficient, $D_{y}$, which might be dependent on the energy dissipation and the droplet rising velocity [8]. The second term on the right hand side is the rate at which the droplets entering the LLEC with volumetric flow rate, $Q_{y, \text { in }}$, that is perpendicular to the column cross-sectional area, $A_{c}$, at a location $z_{y}$ with an inlet number density, $f_{y}^{i n}$, and is treated as a point source in space. The dispersed phase velocity, $u_{y}$, relative to the walls of the column is determined in terms of the relative (slip) velocity with respect to the continuous phase and the continuous phase velocity, $u_{x}$, with respect to the walls of the column as follows: 


$$
u_{y}=u_{s}-u_{x}
$$

The velocity, $u_{s}$, appearing in the above equation could be related to the single droplet terminal velocity, $u_{t}$, to take into account the droplet swarm (the effect of the dispersed phase hold up, $\phi_{y}$ ) and the flow conditions in a specific equipment:

$$
u_{s}=K_{v}\left(1-\phi_{y}\right)^{m} u_{t}(d, \boldsymbol{P})
$$

where $m$ is called the velocity exponent in LLECMOD and may be function of the Reynolds number of the liquid droplet [10]. The elements of the vector $\boldsymbol{P}$ consists of the system physical properties $([\mu \rho \sigma])$, and $K_{v}$ is a slowing factor taking into account the effect of the column internal geometry on the droplet terminal velocity $\left(0<K_{v} \leq 1\right)[8,32]$. A useful guide for selecting the suitable droplet terminal velocity based on the shape of the droplet (rigid, oscillating or circulating), and hence on the system physical properties, could be found in Gourdon et al. [33].

The solute concentration in the continuous phase, $c_{x}$, is predicted using a component solute balance on the continuous phase [20]:

$$
\begin{aligned}
& \frac{\partial\left(\phi_{x} c_{x}\right)}{\partial t}-\frac{\partial}{\partial z}\left(u_{x} \phi_{x} c_{x}+D_{x} \frac{\partial\left(\phi_{x} c_{x}\right)}{\partial z}\right) \\
& =\frac{Q_{x}^{i n} c_{x}^{i n}}{A_{c}} \delta\left(z-z_{y}\right)-\int_{0}^{\infty} \int_{0}^{c_{y, \max }} \dot{c}_{y} v(d) f_{d, c_{y}}(\psi) \partial d \partial c_{y}
\end{aligned}
$$

Note that the volume fraction of the continuous phase, $\phi_{x}$, satisfies the physical constraint: $\phi_{x}+\phi_{y}=1$. The left hand side of Eq.(4) as well as the first term on the right hand side have the same interpretations as those given in Eq.(1); however, with respect the continuous phase. The last term appearing in Eq.(4) is the total rate of solute transferred from the continuous to the dispersed phase, where the liquid droplets are treated as point sources. Note that Eq.(1) is coupled to the solute balance in the continuous phase given by Eq.(4) through the convective and the source terms. The bivariate source term appearing in Eq.(1) due droplet breakage and coalescence is given by the set of equations shown in Table 1 below [20].

Note that in the source terms given in Table $\mathbf{1}$ above, the breakage and coalescence frequencies are given by: $\Gamma$ and $\omega$ respectively, while $\beta_{n}$ is the daughter droplet distribution resulting from the breakage of mother droplet of volume $v^{\prime}$.

\section{MASS TRANSFER COEFFICIENTS}

The individual mass transfer coefficients for the dispersed and continuous phases are found dependent on the behavior of the single droplet in the sense whether it is stagnant, circulating or oscillating [34]. In LLECMOD many available phenomenological and experimentally correlated mass transfer models are included [35-41]. Accordingly, the resistance in series combination of these individual mass transfer coefficients results in the overall mass transfer coefficient, $K_{o y}$, which can be used to predict the rate of change of solute concentration in the liquid droplet as expressed in terms of the droplet volume average concentration:

$\frac{\partial c_{y}(z, t)}{\partial t}=\frac{6 K_{o y}}{d}\left(c_{y}^{*}\left(c_{x}\right)-c_{y}(z, t)\right)$

Note that $K_{o y}$ may be a function of the droplet diameter, $d$, and time depending on the internal state of the droplet; that is, whether it is circulating or behaving like a rigid

\begin{tabular}{|c|c|}
\hline Birth by breakage & $\int_{d}^{d_{\max }} \int_{0}^{c_{y, \max }} \Gamma\left(d^{\prime}, \phi_{y}, \boldsymbol{P}\right) \beta_{n}\left(d^{\prime} d^{\prime}\right) f_{d, c_{y}}\left(d^{\prime}, c^{\prime}{ }_{y}^{\prime} ; t, z\right) \delta\left(c_{y}^{\prime}-c_{y}\right) \partial d^{\prime} \partial c_{y}^{\prime}$ \\
\hline Death by breakage & $-\Gamma\left(d, \phi_{y}, \boldsymbol{P}\right) f_{d, c_{y}}\left(d, c_{y} ; t, z\right)$ \\
\hline Birth by coalescence & $\begin{array}{c}\frac{1}{2} \int_{0}^{d} \int_{c_{y, \text { min }}^{\prime}}^{c_{y, \max }^{\prime}} \omega\left(d^{\prime}, \eta, \phi_{y}, \boldsymbol{P}\right)\left(\frac{d}{\eta}\right)^{5} f_{d, c_{y}}\left(d^{\prime}, c_{y}^{\prime} ; t, z\right) f_{d, c_{y}}\left(\eta, c_{y}^{\prime \prime} ; t, z\right) \partial d^{\prime} \partial c_{y}^{\prime}, \\
\eta=\left(d^{3}-d^{\prime 3}\right)^{1 / 3}, c_{y}^{\prime \prime}=\frac{c_{y} v(d)-c_{y}^{\prime} v\left(d^{\prime}\right)}{v(d)-v\left(d^{\prime}\right)} \\
c_{y, \min }^{\prime}=\max \left(0, c_{y, \max }\left(1-v(d) / v\left(d^{\prime}\right)\left(1-c_{y} / c_{y, \max }\right)\right)\right), \\
c_{y, \max }^{\prime}=\min \left(c_{y, \max },\left(v(d) / v\left(d^{\prime}\right)\right) c_{y}\right)\end{array}$ \\
\hline Death by coalescence & $f_{d, c_{y}}\left(d, c_{y} ; t, z\right) \int_{0}^{\left(d_{\max }^{3}-d^{3}\right)^{3 / 3}} \int_{0}^{c_{y, \max }} \omega\left(d, d^{\prime}, \phi_{y}, \boldsymbol{P}\right) f_{d, c_{y}}\left(d^{\prime}, c_{y}^{\prime} ; t, z\right) \partial d^{\prime} \partial c_{y}^{\prime}$ \\
\hline
\end{tabular}
sphere. The overall mass transfer coefficient is usually expressed using the two-resistance theory in terms of the indi-

Table 1. The Bivariate Source Term for the SDPBE (see Eq. (1)) 
vidual mass transfer coefficients for the continuous and the dispersed phases and $c_{y}^{*}=\left(\partial c_{y} / \partial c_{x}\right) c_{x}[1]$.

\section{MODEL DISCRETIZATION}

\section{Internal Coordinate Discrete Discretization: Detailed Model}

The model discretization proceeds formally by first applying the quadrature method of moments (QMOM) [42] to integrate out the solute concentration after multiplying Eq.(1) by $c_{y}^{m} v(d)$ (with $m=0$ and 1) and integrating it from 0 to $c_{y, \max }$, which results in two coupled marginal densities: $f_{d}(d, z, t)$ and $q(d, z, t)=\int_{0}^{c_{y, \max }} c_{y} v(d) f_{d, c_{y}}(\psi) \partial c_{y} \quad[20,30]$. To close the integrals appearing in the source terms of Table 1 above (representing them in terms of either $f_{d}$ or $q$ ), the bivariate density function $f_{d, c_{y}}$ is expanded as a product of the marginal density $f_{d}$ and a Dirac delta function centered at the solute concentration $\hat{c}_{y}(d)$ : $f_{d, c_{y}}=f_{d}(d ; z, t) \delta\left(c_{y}-\hat{c}_{y}(d)\right)$. Using this, the following set of population balance equations could be obtained [20]:

$$
\begin{aligned}
& \frac{\partial q(d ; z, t)}{\partial t}+\frac{\partial}{\partial z}\left[\bar{u}_{y} q(d ; z, t)-\bar{D}_{y} \frac{\partial q(d ; z, t)}{\partial z}\right] \\
& =\frac{Q_{y}^{i n}}{A_{c}} \frac{c_{y}^{i n} f^{i n}(t)}{v_{i n}} \delta\left(z-z_{y}\right) \\
& +\int_{0}^{c_{y, \max }} \dot{c}_{y} f_{d, c_{y}}\left(d, c_{y} ; z, t\right) \partial c_{y}+\pi_{q}\left(f_{d}, q, \bar{c}_{y}\right) \\
& \frac{\partial f_{d}(d ; z, t)}{\partial t}+\frac{\partial}{\partial z}\left[u_{y} f_{d}(d ; z, t)-D_{y} \frac{\partial f_{d}(d ; z, t)}{\partial z}\right] \\
& =\frac{Q_{y}^{i n}}{A_{c}} \frac{f^{i n}}{v_{i n}}(t) \delta\left(z-z_{y}\right)+\pi_{n}\left(f_{d}, \bar{c}_{y}\right)
\end{aligned}
$$

here $q=\hat{c}_{y}(d) v(d) f_{d}$ and $\left(\bar{u}_{y}, \bar{D}_{y}\right)$ are evaluated at the mean solute concentration $\left(\bar{c}_{y}\right)$. The expressions of the source terms $\pi_{n}=\pi_{n}^{b}+\pi_{n}^{c}$ and $\pi_{q}=\pi_{q}^{b}+\pi_{q}^{c}$ are presented in Table 2.

The two population balance equations given by Eqs. $(6 \&$ 7) represent an infinite set of partial differential equations in terms of droplet size $d$. To reduce this to a finite set of partial differential equations, the marginal density $f_{d}$ is expanded in terms of a set of Dirac delta functions with distinct weights and positions as:

$f(d ; z, t)=\sum_{i=1}^{N_{p}} w_{i} \delta\left(d-d_{i}\right)$

where $d_{i}$ is the representative size of the droplet positioned at the center of the partition: $\left[d_{i-1 / 2}, d_{i+1 / 2}\right], i=1,3, \ldots N_{p}$. Note that the number of partitions is arbitrary and is equal to $N_{p}$. The weight of the droplets $w_{i}$ is given by:

$w_{i}(z, t)=\int_{d_{i-1 / 2}}^{d_{i+1 / 2}} f_{d}(d ; z, t) \partial d$

and physically is the total droplet concentration in the $i$ th partition (number per unit volume of the coexisting phases).

The corresponding solute concentration of these droplets in the $i$ th partition is given by:

$\bar{c}_{y, i}=\left\{\begin{array}{l}\frac{q_{i}}{v\left(d_{i}\right) w_{i}}, \text { if }, \quad w_{i}>\sqrt{\varepsilon_{p}} \\ 0, \text { otherwise }\end{array}\right.$

where $\varepsilon_{p}$ is the machine epsilon.

Now by substitution of Eq. (8) into Eqs. (6 \& 7) and integrating both sides over the partition: $\left[d_{i-1 / 2}, d_{i+1 / 2}\right], i=1,3, \ldots N_{p}$, one can get the following finite set of partial differential equations:

Table 2. The Source Terms for the SDPBEs Given by Eqs.(6 \& 7)

\begin{tabular}{|c|c|}
\hline $\boldsymbol{\pi}_{\boldsymbol{n}}^{b}$ & $-\Gamma\left(v, \bar{c}_{y}, \phi_{y}, \boldsymbol{P}\right) f_{v}(v ; t, z)+\int_{v}^{v_{\max }} \Gamma\left(v^{\prime}, \bar{c}_{y}, \phi_{y}, \boldsymbol{P}\right) \beta_{n}\left(v \mid v^{\prime}\right) f_{v}\left(v^{\prime} ; t, z\right) \partial v^{\prime}$ \\
\hline $\boldsymbol{\pi}_{\boldsymbol{n}}^{\boldsymbol{c}}$ & $-f_{v}(v ; t, z) \int_{0}^{v_{\max }-v} \omega\left(v, v^{\prime}, \bar{c}_{y}, \phi_{y}, \boldsymbol{P}\right) f_{v}\left(v^{\prime} ; t, z\right) \partial v^{\prime}+\frac{1}{2} \int_{0}^{v} \omega\left(v^{\prime}, \bar{c}_{y}, \lambda, \phi_{y}, \boldsymbol{P}\right) f_{v}\left(v^{\prime} ; t, z\right) f_{v}(\lambda ; t, z) \partial v^{\prime}, \lambda=v^{\prime}-v^{\prime}$ \\
\hline $\boldsymbol{\pi}_{\boldsymbol{q}}^{b}$ & $-\Gamma\left(v, \bar{c}_{y}, \phi_{y}, \boldsymbol{P}\right) q(v ; t, z)+\int_{v}^{v_{\max }} \Gamma\left(v^{\prime}, \bar{c}_{y}, \phi_{y}, \boldsymbol{P}\right) \beta_{n}\left(v \mid v^{\prime}\right) q\left(v^{\prime} ; t, z\right) \partial v^{\prime}$ \\
\hline $\boldsymbol{\pi}_{\boldsymbol{q}}^{\boldsymbol{c}}$ & $-q(v ; t, z) \int_{0}^{v_{\max }-v} \omega\left(v, v^{\prime}, \bar{c}_{y}, \phi_{y}, \boldsymbol{P}\right) q\left(v^{\prime} ; t, z\right) \partial v^{\prime}+\frac{1}{2} \int_{0}^{v} \omega\left(v^{\prime}, \bar{c}_{y}, \lambda, \phi_{y}, \boldsymbol{P}\right)\left(\frac{v^{\prime}}{v}\right) q\left(v^{\prime} ; t, z\right) f_{v}(\lambda ; t, z) \partial v^{\prime}$ \\
& $+\frac{1}{2} \int_{0}^{v} \omega\left(v^{\prime}, \bar{c}_{y}, \lambda, \phi_{y}, \boldsymbol{P}\right)\left(\frac{\lambda}{v}\right) q(\lambda ; t, z) f_{v}\left(v^{\prime} ; t, z\right) \partial v^{\prime}, \lambda=v-v^{\prime}$ \\
\hline
\end{tabular}




$$
\begin{aligned}
& \frac{\partial \varphi_{i}(z, t)}{\partial t}+\frac{\partial}{\partial z}\left[\bar{u}_{y, i} \varphi_{i}(z, t)-\bar{D}_{y} \frac{\partial \varphi_{i}(z, t)}{\partial z}\right]= \\
& \frac{Q_{y}^{i n}}{A_{c}} \varphi_{i}^{i n}(t) \delta\left(z-z_{y}\right)+\pi_{n, i} \\
& \frac{\partial q_{i}(z, t)}{\partial t}+\frac{\partial}{\partial z}\left[\bar{u}_{y, i} q_{i}(d ; z, t)-\bar{D}_{y} \frac{\partial q_{i}(d ; z, t)}{\partial z}\right]= \\
& \frac{Q_{y}^{i n}}{A_{c}} c_{y}^{i n} \varphi_{i}^{i n}(t) \delta\left(z-z_{y}\right)+\frac{6 K_{o y, i}}{d_{i}}\left(\varphi_{i} c_{y}^{*}\left(c_{x}\right)-q_{i}\right)+\pi_{q, i}
\end{aligned}
$$

Since measuring the solute concentration of a specific group of droplet in any partition $i$ is impractical, the mean solute concentration in all the partitions (mixed cup concentration) is of practical importance and is given by:

$$
\bar{c}_{y}=\frac{\sum_{i=1}^{M_{x}} \bar{c}_{y, i} w_{i} v\left(d_{i}\right)}{\sum_{i=1}^{M_{x}} w_{i} v\left(d_{i}\right)}=\frac{\sum_{i=1}^{M_{x}} q_{i}}{\sum_{i=1}^{M_{x}} \varphi_{i}}
$$

where $\varphi_{i}$ is the volume fraction of the dispersed phase droplets in the $i$ th partition and the total volume fraction (hold up) of the dispersed phase is:

$\phi_{y}=\sum_{i=1}^{N_{p}} \varphi_{i}$

The discrete form of the source terms given in Table 2 could be written as follows [19]:

$$
\begin{aligned}
& \pi_{n, i}^{b}=-\Gamma_{i} w_{i}+\sum_{k=i}^{M_{x}} \Pi_{i, k} \Gamma_{k} w_{k} \\
& \pi_{q, i}^{b}=-\Gamma_{i} q_{i}+\sum_{k=i}^{M_{x}} \Pi_{i, k} \Gamma_{k} q_{k} \\
& \pi_{n, i}^{c}=-\varphi_{i} \sum_{k=1}^{\operatorname{Mmax}(i)} \omega_{i, k} \frac{\varphi_{k}}{v\left(d_{k}\right)} \\
& +\sum_{k=\operatorname{Kmin}(i)}^{\operatorname{Kmax}(i)} \sum_{j=\operatorname{Jmin}(i, k)}^{\operatorname{Jmax}(i, k)} \omega_{k, j} \Psi_{k, j}^{<i>} \varphi_{k} \varphi_{j} \\
& \pi_{q, i}^{c}=-q_{i} \sum_{k=1}^{\operatorname{Mmax}(i)} \omega_{i, k} \frac{\varphi_{k}}{v\left(d_{k}\right)} \\
& +\sum_{k=\operatorname{Kmin}(i)}^{\operatorname{Kmax}(i)} \sum_{j=J \min (i, k)}^{J \max (i, k)} \omega_{k, j} \Psi_{k, j}^{<i>} \\
& {\left[\left(\frac{v\left(d_{k}\right)}{v\left(d_{j}\right)+v\left(d_{k}\right)}\right) \varphi_{j} q_{k}+\left(\frac{v\left(d_{j}\right)}{v\left(d_{j}\right)+v\left(d_{k}\right)}\right) \varphi_{k} q_{j}\right]}
\end{aligned}
$$

The $i$ th interaction coalescence matrix, $\Psi_{k, j}^{<i>}$, represents the effective number of coalescence events reporting in the $i$ th partition with coalescence frequency $\omega$, while $\Pi_{i, k}$ is an upper triangular breakage matrix that depends solely on the daughter droplet distribution $\beta_{n}$. For more details and implementation aspects, the interested reader could refer to Attarakih et al. $[19,20]$. Note that the source term given by Eq. (16 \& 18) takes into account the presence of mass transfer and could be reduced to the pure hydrodynamic source term given by Eq. $(15 \& 17)$ by setting $\bar{c}_{y, i}=1\left(q_{i}=\varphi_{i}\right)$. The indices appearing on the summations in the loss and formation terms for droplet coalescence: $\operatorname{Kmin}(i))$, $K \max (i), \operatorname{Mmax}(i), \operatorname{Jmin}(i, k)$ and $\operatorname{Jmax}(i, k)$ represent the locations of the nonzero elements of the $i$ th interaction matrix and depend on the droplet diameter grid structure once it becomes available.

To complete the mathematical model described above, boundary and initial conditions are required. Concerning the boundary conditions, we adopted those of Wilburn [43], while the inlet bivariate number density is taken as: $f_{d, c_{y}}^{\text {in }}\left(d, c_{y} ; t\right)=f_{d}^{i n}(d ; t) \times c_{y}^{i n}$, which means that all the inlet droplets have the same uniform solute concentration.

\section{Internal Coordinate Discretization: Reduced Model}

The solute population balance equation (Eq. (7)) could be further reduced in terms of the mean solute concentration $\left(\bar{c}_{y}\right)$ for all droplets having sizes in the range: $[d, d+\partial d]$ at any point in space and time. This is done by expanding the bivariate density function as $f_{d, c_{y}}=f_{d}(d ; z, t) \delta\left(c_{y}-\bar{c}_{y}(z, t)\right)$. The formal substitution of the last expansion in Eq. (6) after multiplying it by $c_{y} v(d)$ and integrating with respect to $c_{y}$ from zero to $c_{y, \max }$ and with respect to $d$ from $d_{\min }$ to $d_{\max }$ one can get the mean solute concentration in the dispersed phase:

$$
\begin{aligned}
& \frac{\partial\left[\bar{c}_{y} \phi_{y}\right]}{\partial t}+\frac{\partial}{\partial z}\left[\bar{c}_{y} \bar{F}(t, z)-\bar{D}_{y} \frac{\partial\left[\bar{c}_{y} \phi_{y}\right]}{\partial z}\right]= \\
& \frac{Q_{y}^{i n}}{A_{c}} \bar{c}_{y}^{i n} \delta\left(z-z_{y}\right)+\bar{K}_{o y}\left(c_{y}^{*}\left(c_{x}\right)-\bar{c}_{y}\right) \\
& \bar{F}_{y}=\int_{d_{\min }}^{d_{\max }} u_{y}\left(\bar{c}_{y}, d\right) v(d) f_{d}(d, z, t) \partial d \\
& \approx \sum_{i=1}^{N_{p}} u_{y}\left(\bar{c}_{y}, d_{i}\right) \varphi_{i} \\
& \bar{K}_{o y}=\int_{d_{\min }}^{d_{\max }} \frac{6 K_{o y}\left(d, \bar{c}_{y}\right)}{d} v(d) f_{d}(d, z, t) \partial d \\
& \approx \sum_{i=1}^{N_{p}} \frac{6 K_{o y}\left(d_{i}, \bar{c}_{y}\right)}{d_{i}} \varphi_{i}
\end{aligned}
$$

The solute concentration in the continuous phase reads: 


$$
\begin{aligned}
& \left.\frac{\partial\left[\bar{c}_{x} \phi_{x}\right]}{\partial t}-\frac{\partial}{\partial z}\left[\bar{c}_{x} \phi_{x} \bar{u}_{x}\right)+\bar{D}_{x} \frac{\partial\left[\bar{c}_{x} \phi_{x}\right]}{\partial z}\right]= \\
& \frac{Q_{x}^{i n}}{A_{c}} \bar{c}_{x}^{i n} \delta\left(z-z_{y}\right)-\bar{K}_{o y}\left(c_{y}^{*}\left(c_{x}\right)-\bar{c}_{y}\right)
\end{aligned}
$$

Note that three types of the continuous phase velocity $\bar{u}_{x}$ can be distinguished: the steady state, oscillatory and nonoscillatory models [19] and are given in the appendix.

\section{SPATIAL COORDINATE DISCRETIZATION}

Eqs . (11), (12) and (20) (detailed model) or (11), (19) and (20) (reduced model) represent a system of conservation laws that are coupled through the convective and source terms and are dominated by the convective term for typical values of $\bar{D}_{y}$ and $\bar{u}_{y}$ encountered in LLECs (Peclet No. $\approx 1 \times 10^{3} H_{k}-2 \times 10^{3} H_{k}$ ). Due to the dominance of the convective term it is expected that the hold up profile in each partition $\left(\varphi_{i}\right)$ will move as a function of time along the column height with a steep front. Therefore, accurate front tracking discretization approaches are to be used such as the non-oscillatory first and second order central difference schemes [44]. Let the $i$ th convective flux be denoted as $F_{i}=\bar{u}_{y, i} \varphi_{i}$ and the staggering spatial grid: $z_{l \pm 1 / 2}=z_{l} \pm \Delta z / 2$ and the average cell hold up as $\varphi_{i, l}=\int_{z_{l-1 / 2}}^{z_{l+1 / 2}} \varphi_{i}(t, z) \delta z / \Delta z$. The convective flux is then discretized in conservative form using the Kurganove and Tadmor [44] central difference schemes (see Attarakih et al. [19]) for a detailed spatial discretization algorithm), while the implicit Euler method by lagging the non-linear terms is used for time discretization. The resulting system of algebraic equations is diagonally dominant and hence it converges to the steady state solution with negligible sensitivity to the magnitude of the time step [19].

\section{SAMPLE PROBLEMS}

\section{Parameter Estimation Using an RDC Column (DN-150)}

In this section a sample problem is considered to illustrate the basic features of the LLECMOD and the coalescence parameters estimation package including the main input parameters and the user input functions. For this purpose, the steady state experimental data for the hydrodynamics of a laboratory scale RDC column whose dimensions are shown in Table $\mathbf{3}$ were utilized initially to estimate the coa- lescence parameters. The chemical system used is the EFCE test system: water/n-butyl acetate whose physical properties are available online (http//dechema.de/ extraktion). Due to the relatively low interfacial tension of this system, the droplet coalescence as well as breakage has an important effect on the column hydrodynamics.

Additionally, the experimentally correlated droplet transport functions, the breakage frequency and the daughter droplet distribution based on the work of Modes [62] and Schmidt et al. [54] were used. These were determined based on single droplet experiments carried out in a column segment having one compartment of the total height of $0.03 \mathrm{~m}$.

The droplet rise velocities and the breakage probability functions are determined using digital image processing, while the axial dispersion coefficient of the dispersed phase is determined using residence time distribution analysis for a mono-dispersion of droplets of specified diameters. The dispersion coefficient of the continuous phase was taken from the work of Steiner and Hartland [73]. As a suitable velocity law based on the selection chart detailed in the book of Godfrey and Slater [2], the Klee and Treybal [45] velocity law was used to estimate the terminal droplet velocity, which was then multiplied by $\left(1-\phi_{y}\right)$ to take into account the droplet swarm effect. The slowing factor, $K_{v}$, of Modes [62], adapted after a correlation of Godfrey and Slater [50], and the axial dispersion coefficient, $\bar{D}_{y}$, are:

$$
\begin{aligned}
K_{v}(d, N) & =1-1.037\left(N^{3} D_{R}^{5}\right)^{0.12} \\
& -0.62\left(\frac{d}{D_{s}-D_{R}}\right)^{0.44} \\
\frac{\bar{D}_{y}}{\bar{u}_{y} H_{K}}= & 0.0138+8.26 \times 10^{-7}\left(\frac{N D_{R}}{\bar{u}_{y}}\right)^{3.3}
\end{aligned}
$$

where $N$ is the rotor speed $\left(\mathrm{s}^{-1}\right), D_{R}$, and $D_{s}$ are the rotor and stator diameters, respectively.

The droplet breakage frequency and the daughter droplet distribution are correlated based on single droplet experiments and are given by:

$\Gamma\left(d, \phi_{y}\right)=P_{r}(d, N) \frac{\left|\bar{u}_{y}\left(d, \phi_{y}\right)\right|}{H_{c}}$

The breakage probability, $p_{r}$, is correlated with the system physical properties and the energy dissipation in the

Table 3. RDC Column Geometry

\begin{tabular}{|c|c|c|c|c|c|}
\hline Column diameter & $(\mathrm{m})$ & 0.15 & Column height & $(\mathrm{m})$ & 2.550 \\
\hline Stator diameter & $(\mathrm{m})$ & 0.105 & Dispersed phase inlet & $(\mathrm{m})$ & 0.250 \\
\hline Rotor diameter & $(\mathrm{m})$ & 0.090 & Continuous phase inlet & & 2.250 \\
\hline Compartment height & $(\mathrm{m})$ & 0.030 & & \\
\hline
\end{tabular}


following form after Modes [62] based on a correlation after Cauwenberg et al. [74]:

$$
\begin{aligned}
& \frac{p_{r}}{1-p_{r}}=1.2 \cdot 10^{-6} \cdot \\
& {\left[\frac{\rho_{x}^{0.8} \mu_{x}^{0.2} d D_{R}^{1.6}(2 \pi)^{1.8}\left(N^{1.8}-N_{\text {crit. }}^{1.8}\right)}{\sigma}\right]^{2.88}}
\end{aligned}
$$

where $N_{R, \text { crit }}$ is the critical rotor speed below which the breakage probability falls to zero and $H_{c}$ is the RDC compartment height. The daughter droplet distribution is assumed to follow the beta distribution [74]:

$$
\beta_{n}\left(d \mid d^{\prime}\right)=3 \vartheta(\vartheta-1)\left[1-\left(\frac{d}{d^{\prime}}\right)^{3}\right]^{(\vartheta-2)} \frac{d^{2}}{d^{3}}
$$

where $\vartheta$ is the mean number of daughter droplets produced upon breakage of mother droplet of the diameter $d^{\prime}$. It is experimentally correlated and found dependent on the energy dissipation having a value $\geq 2$.

First, the coalescence constants were estimated for the system water/n-butyl acetate using the coalescence parameter estimation package (s. appendix) at different rotational speeds. The detailed internal RDC column geometry is shown in Fig. (1), which is based on the values given in Table 3.

Fig. (2) shows the results of fitting the steady state cumulative volume distribution at the outlet of the fivecompartment $\mathrm{RDC}$ column using 30 experimental data points. It is evident that there is a very good agreement between the experimental and predicted densities. The mean values of the estimated coalescence parameters are: $C_{3}=0.0694$ and $C_{4}=1.3 \times 10^{11} \mathrm{~m}^{-2}$, where the objective function (Eq. (28)) is not very sensitive to changes in the values of the constant $C_{4}$. This constant may vary $+/-50 \%$, which agrees to the reported results in the published literature (Alopaeus et al. [18,65]).

Second, the estimated parameters above were used to simulate a pilot plant RDC column with the total active height of $1.76 \mathrm{~m}$, where its characteristic dimensions are shown in Table 3. In all the numerical simulations the inlet feed distribution is based on the measured values. The numerical integration is carried out using the IME FVS solver with grid, having a dimension of $70 \times 20$. The doubling of the grid size shows no principal differences in the predicted results. The minimum droplet diameter is chosen to lie above the critical droplet diameter for stable droplets, according to Schmidt et al. [54]:

$$
\begin{aligned}
& N_{\text {crit }}=0.016 \frac{D_{R}^{-2 / 3} \mu_{y} d^{-4 / 3}}{\left(\rho_{x} \rho_{y}\right)^{1 / 2}}+ \\
& {\left[\left(0.008 \frac{D_{R}^{-2 / 3} \mu_{y} d^{-4 / 3}}{\left(\rho_{x} \rho_{y}\right)^{1 / 2}}\right)^{2}+0.127 \frac{\sigma}{\rho_{x} D_{R}^{4 / 3} d^{5 / 3}}\right]^{0,5}}
\end{aligned}
$$

The user input parameters using the LLECMOD main input dialog are shown in Fig. (1). The input parameters and data shown in Fig. (1) and Fig. (A1) are echoed on the LLECMOD working space before the space time integrator is started. When the final simulation time is exceeded or the steady state tolerance is achieved the LLECMOD presents the results in graphical form showing the most important data for the simulation such as the hold-up, Sauter diameter and droplet size distribution as well as a summary of the simulation results displayed in a separate window.

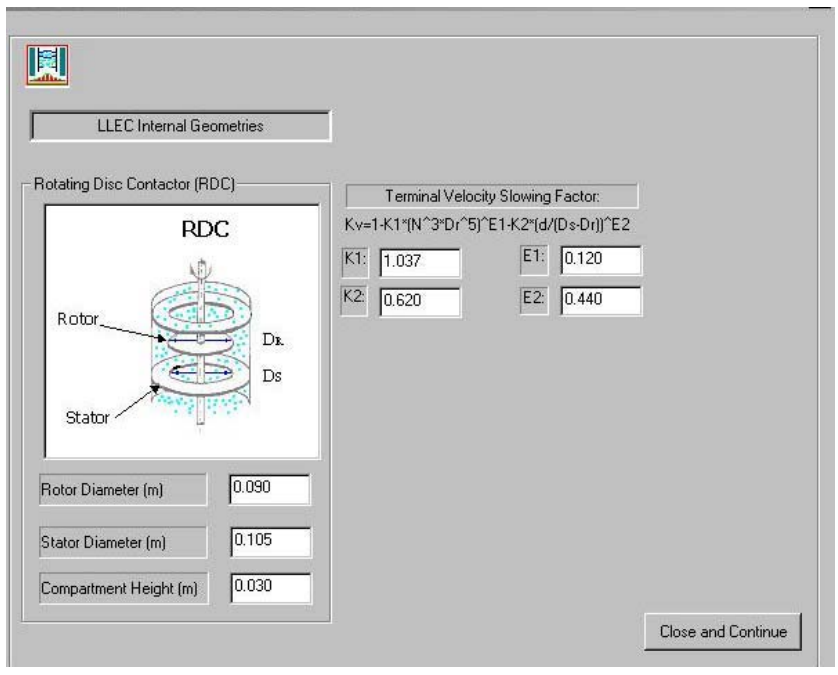

Fig. (1). The LLECMOD input dialog for internal RDC column geometries.

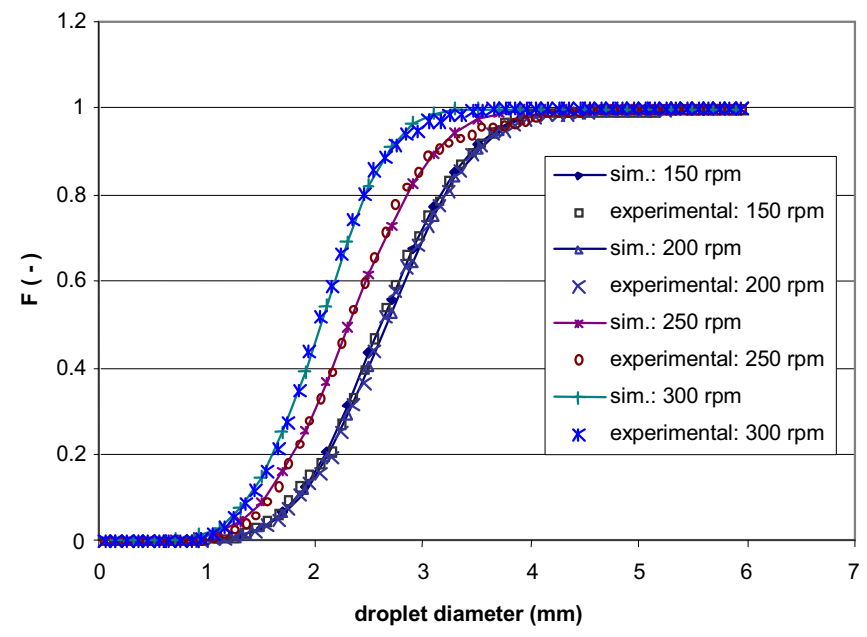

Fig. (2). Comparison between the modelled and experimental cumulative volume distribution at the outlet of a short segment RDC column at steady state for the system water/n-butyl acetate.

Fig. (3) depicts the cumulative droplet volume distributions at the top of the column using two agitator speeds: 150 and $200 \mathrm{rpm}$. It is evident that the two steady state distributions are well predicted and the volumetric distribution is shifted to the left as the rotor speed is increased indicating the increase of the breakage rate. This fact is elucidated by closely examining the hold-up profiles Fig. (4), where the hold-up at $200 \mathrm{rpm}$ rotor speed is increased due to the increase of small droplets residence time. Although the steady state hold-up profiles were not accurately predicted, espe- 
cially at the bottom of the column, the general trend is predicted.

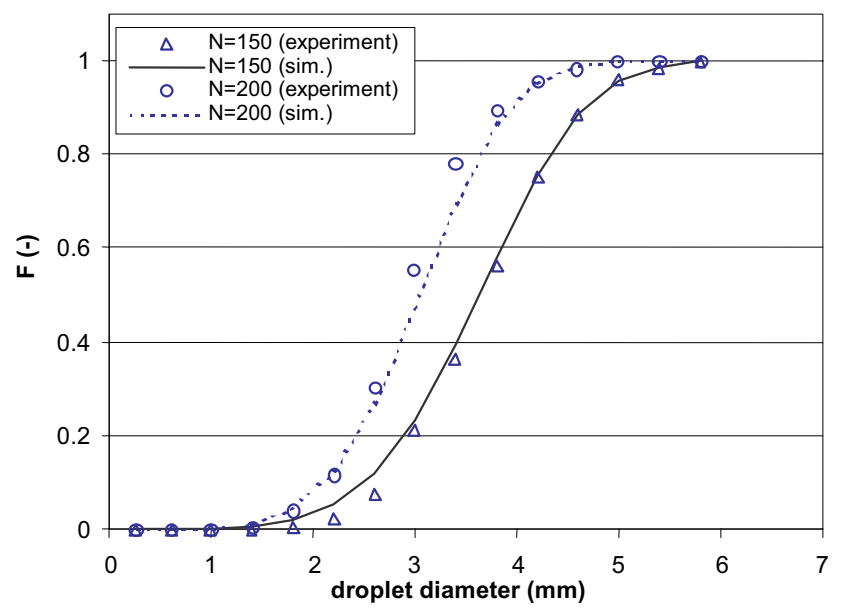

Fig. (3). Comparison between the modelled and experimental cumulative volume distribution at the outlet of a pilot plant RDC column at steady state using the system water/n-butyl acetate.

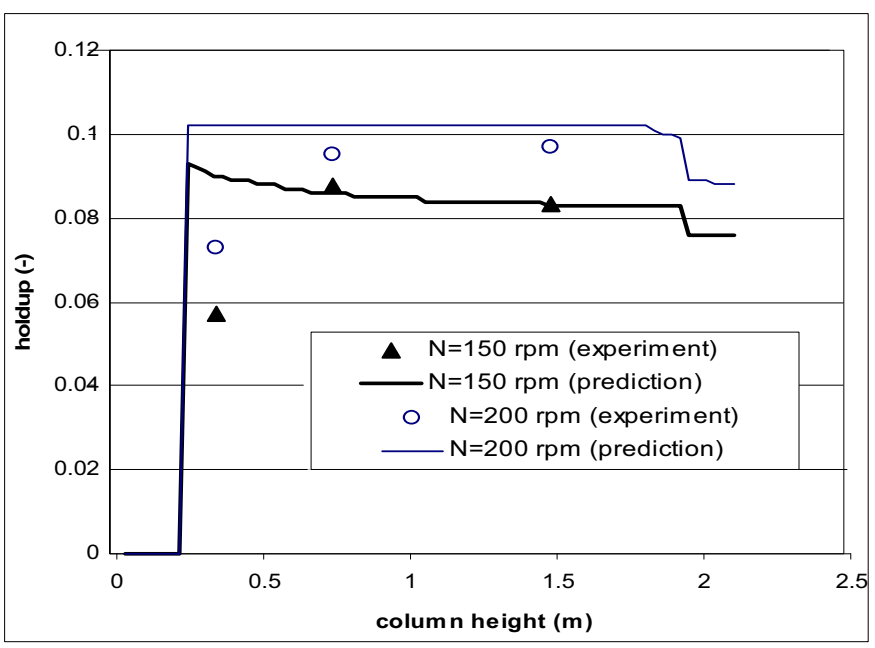

Fig. (4). Predicted and simulated hold-up profiles in a pilot plant RDC column at different rpm using the system water/n-butyl acetate.

The CPU time requirements on a PC of $700 \mathrm{MHz}$ speed for this case is $128 \mathrm{~s}$ using a steady state tolerance of $10^{-10}$; however, this time could be reduced if larger tolerance value is used. The performance of the other solvers has been extensively tested by Attarakih et al. [19], and was found to produce identical results at steady state. However, for transient simulations the first order solvers (IME FVS and IME KT1) suffer from numerical diffusion due to the steep moving fronts of the droplets hold-up of different sizes. This numerical diffusion is greatly reduced when the second order solver (IME KT2) is used and, thus the moving fronts can be captured correctly.

Fig. (5) shows again that the droplet coalescence is dominant at the $150 \mathrm{rpm}$ rotational speed as indicated by the increase of the mean droplet diameter along the column height. As the rotor speed is increased to $200 \mathrm{rpm}$, the two interaction droplet mechanisms (breakage and coalescence) are almost balanced with slight dominance of droplet breakage. This fact is reflected by the model of Tsouris and Tavlarides [17], where the coalescence efficiency decreases as the energy input increases. Moreover, the steady state discontinuities due to the dispersed and continuous phases inlets are highly resolved due to the non-uniform spatial grid used in the simulation. In both experiment the largest experimental error was at the measuring probe at $0.75 \mathrm{~m}$. However, this phenomenon did not repeat with other chemical systems tested [26] and may be due to impurities within the probe.

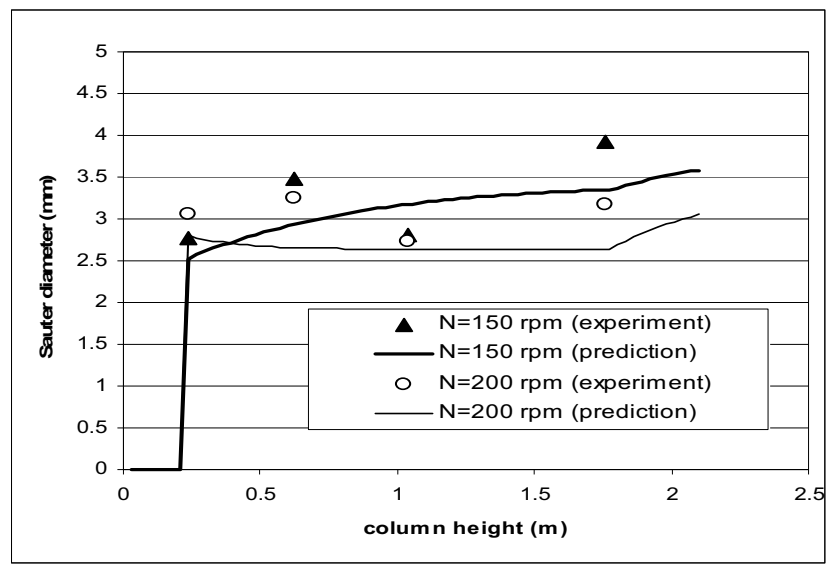

Fig. (5). Predicted and simulated Sauter droplet diameter in a pilot plant RDC column at different agitation using the system water/nbutyl acetate.

Fig. (6) gives the evolution of the dispersed phase flow rate at the top of the column using the oscillatory and nonoscillatory velocity models given in Table A1. It is clear that the two velocity models are only identical at steady state, where the conservation of mass is exactly satisfied.

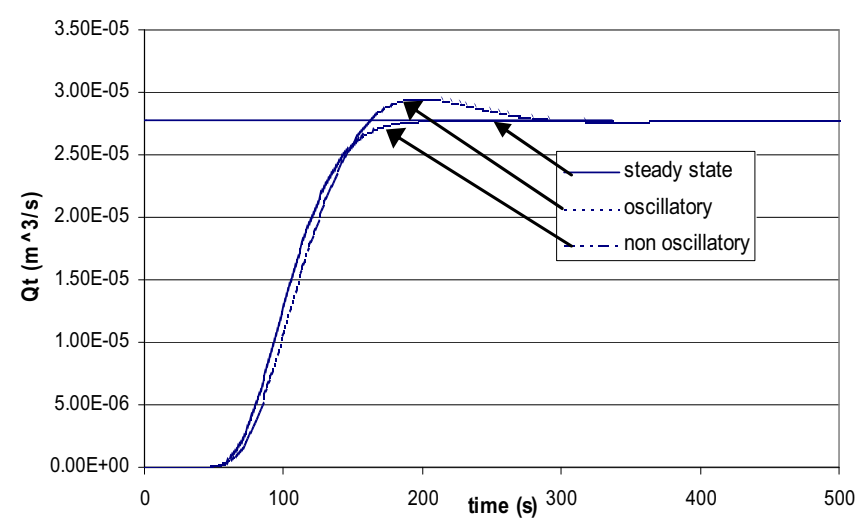

Fig. (6). Comparison between the oscillatory and non-oscillatory velocity models in a pilot plant RDC column at $200 \mathrm{rpm}$ the system water/n-butyl acetate.

\section{SIMULATION OF AN RDC COLUMN (DN-150)}

The hold up, Sauter mean diameter and continuous and disperse phase concentrations profiles are used as experimental reference data in the framework of the AiF-joint project "From single droplet to extraction column" of RWTH Aachen, TU Munich and University Kaiserslautern (see also: http://dechema.de/extraktion "Kolloquium 10. 03. 2005"). In 
Table 4 the most important simulation parameters are summarized with hydrodynamic data from Schmidt [26], and mass transfer data from Garthe [75].

Table 4. Simulation Parameters RDC (DN-150)

\begin{tabular}{|c|c|}
\hline Initial solute concentration (weight-\%) & 5.579 \\
\hline Final solute concentration (weight-\%) & 3.953 \\
\hline Volume flow rate of dispersed phase $(l / h)$ & 48.00 \\
\hline Volume flow rate of water $(l / h)$ & 40.00 \\
\hline Throughput $\left(m^{3} / m^{2} . h\right)$ & 4.987 \\
\hline Phase ratio $\gamma=Q_{y, \text { in }} / Q_{x, i n}$ & 1.20 \\
\hline Stirrer rotational speed (rpm) & 200 \\
\hline
\end{tabular}

Fig. (7) shows the hold-up profile of the disperse phase for the RDC DN-150. The discrepancy of the simulated experimental results from those obtained in the experiment amounts to $5 \%, 20 \%$, and $12 \%$ in the lower, centre and top parts of the column respectively. The hold-up was measured with a gate-valve along the column height, a destructive measuring principle, which delivers reliable results. In Fig. (8) are the simulated and experimental Sauter mean diameter profiles. The relative errors are $10 \%$ and $5 \%$ in the lower and top parts of the column respectively. Fig. (9) shows the simulated and experimental solute concentration profiles in the continuous and dispersed phases along the column height. The relative error is less than $10 \%$, with the exception of the dispersed phase concentration at the column exit. For this specific case, the correlation of Handlos and Baron [36] was used as a mass transfer mode assuming oscillating droplet behavior. Additionally, the correlation of the distribution coefficient according to Schmidt [26] was used. For further simulations, the reader can consult Steinmetz et al. [32], and Schmidt et al. [54].

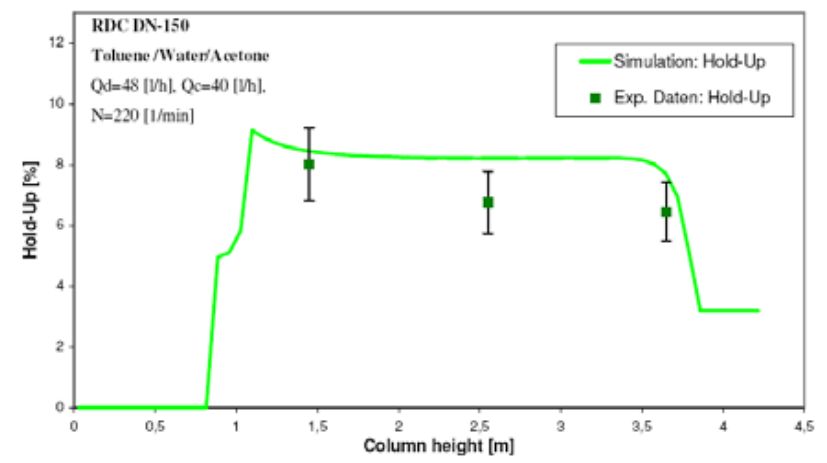

Fig. (7). Comparison of simulated and experimental hold-up profiles for RDC DN-150.

\section{SIMULATION OF A KÜHNI COLUMN (DN-150)}

The simulation of a Kühni column (DN-150) is carried out using LLECMOD with a specified correlations for mass transfer, droplet velocity as well as the breakage and coalescence frequencies. The experimental data at steady state from Zamponi et al. [76], were used for comparison and the simulation parameters are summarized in Table 5. The simu- lations were done at a rotational speed of $160 \mathrm{1} / \mathrm{min}$ with water inflow of $130 \mathrm{l} / \mathrm{h}$ and solvent flow rate of $130 \mathrm{l} / \mathrm{h}, 160$ $\mathrm{l} / \mathrm{h}$ and $190 \mathrm{l} / \mathrm{h}$. Both coalescence parameters, according to the model of Coulaloglou \& Tavlarides [11], were estimated at rotational speed of $160 \mathrm{l} / \mathrm{min}$. The results of simulations at a rotational speed of $190 \mathrm{l} / \mathrm{min}$ show that the hydrodynamics of the column is inaccurately predicted with this parameter set.

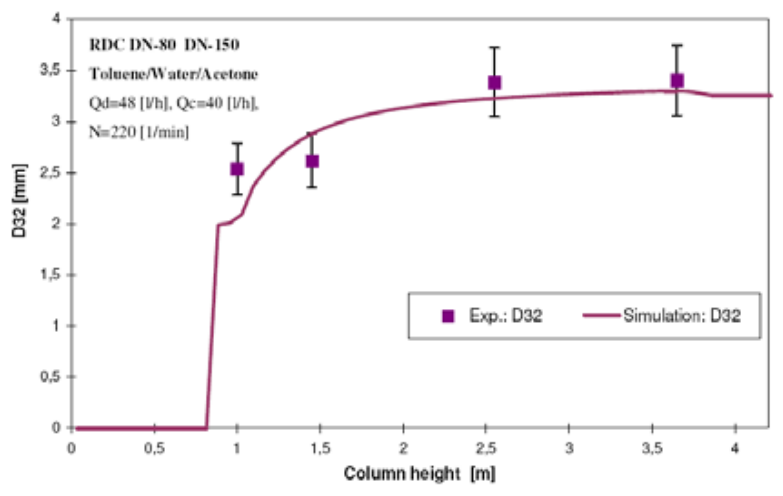

Fig. (8). Comparison of simulated and experimental Sauter mean diameter $\left(d_{32}\right)$ for RDC DN-150 (experimental data are from Garthe [75].

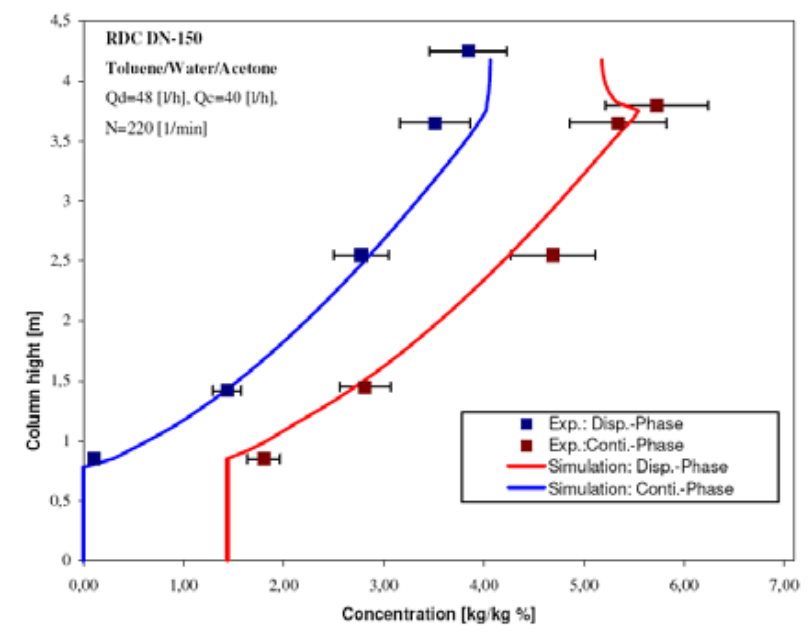

Fig. (9). Comparison between simulated and experimental concentration profiles for RDC DN-150 (experimental data are from Garthe [75]).

Table 5. Simulation Parameters Kühni DN-150

\begin{tabular}{|c|c|}
\hline Initial conc. of solute (weight.-\%) & 5.00 \\
\hline Final conc. of solute (weight.-\%) & 0.00 \\
\hline Volume flow rate of dispersed phase $(1 / \mathrm{h})$ & $130 / 160 / 190$ \\
\hline Volume flow water $(\mathrm{l} / \mathrm{h})$ & 130.00 \\
\hline Throughput $\left(\mathrm{m}^{3} \cdot \mathrm{m}^{-2} \cdot \mathrm{h}^{-1}\right)$ & 16.12 \\
\hline Phase ratio $\gamma=Q_{y, i n} / Q_{x, i n}$ & 1.28 \\
\hline Stirrer speed (rpm) & 160 \\
\hline
\end{tabular}


Fig. (10) shows the hold-up profile at different volumetric flow rates. The relative error in the simulated hold up for different dispersed phase flow rates $(190 \mathrm{l} / \mathrm{h}$ and $160 \mathrm{l} / \mathrm{h})$ is smaller than $5 \%$. It is $8 \%$ for a volumetric flow rate of 130 $1 / \mathrm{h}$. Note that the change in the dispersed phase volumetric flow rate significantly affects the steady state hold up profile.

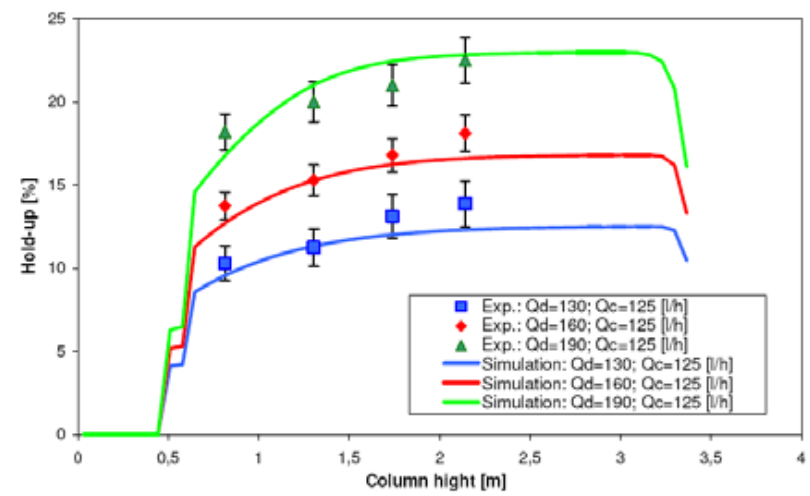

Fig. (10). Hold up profiles for Kühni column DN-150, dispersed phase: toluene (experimental data are from Zamponi [76]).

Fig. (11) shows the concentration profile at rotational speed of $160 \mathrm{rpm}$ and flow rate of the disperse phase of 160 $1 / \mathrm{h}$. The aqueous phase flow rate is $125 \mathrm{l} / \mathrm{h}$ at the initial concentration of 5 weight- $\%$ solute. The simulations were done with the EFCE equilibrium parameter set (Misek et al. [77]), as well as the parameter set corrected by Schmidt [26] by taking into account the concentration dependent distribution coefficient. Comparison between the experimental and calculated concentration profiles over the total column-height show a relative error of less than $5 \%$.

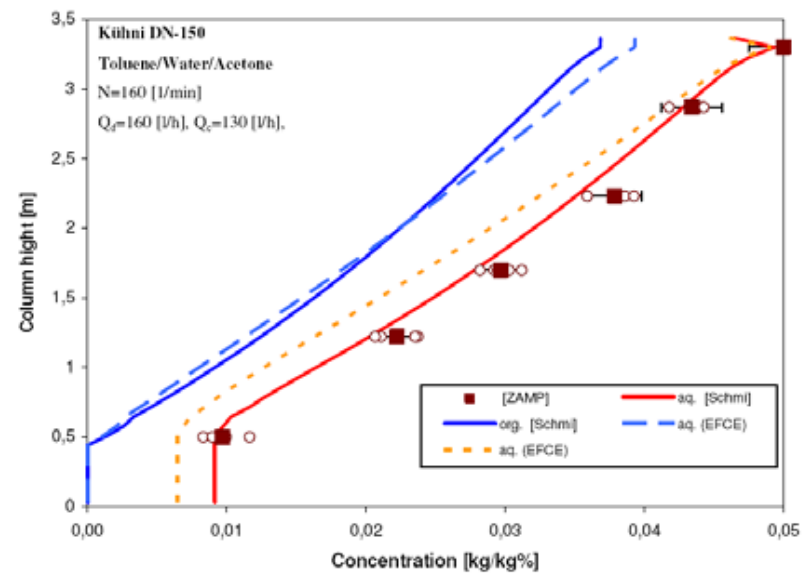

Fig. (11). Concentration profile in a Kühni column DN-150, dispersed phase: toluene (experimental data are from Zamponi [76], solid lines Schmidt [26], dotted lines EFCE).

\section{CONCLUSIONS}

In this work the SDPBE [78] has been solved using the numerical algorithms developed by Attarakih [19,20,29] and are utilized successfully to develop the basic features of a Windows-based program called LLECMOD for the simulation of coupled hydrodynamics and mass transfer for general liquid-liquid extraction columns. A parameter estimation package for the droplet coalescence models is developed

based on the inverse solution of the population balance equation in a short segment of an agitated column. These packages are based on the spatially distributed bivariate population balance equation describing the interacting liquid-liquid dispersions, taking into account droplet transport, breakage and coalescence as well as solute transfer. The user-friendly input dialogs and the user functions input modules make the program very general and simple to use. For steady state simulation purposes, the IME FVS solver is found to be the best when very sharp hold-up profiles are not expected to occur. However, the accuracy of the spatial second order solver (IME KT2) makes it very attractive for transient simulations without appreciable increase in the CPU time. The LLECMOD has extensively validated against experimental data obtained in RDC and Kühni columns of DN-150. It provides a useful tool for the scale up and simulation of agitated liquid extraction columns based on the detail nature of the discrete dispersed phase.

\section{NOTATION}

$A_{c}$

$\mathrm{C}_{\mathrm{i}}$

$c_{x}, \bar{c}_{y}$

$c_{y, \min }^{\prime}, c_{y, \max }^{\prime}$

$\bar{D}_{x}, \bar{D}_{y}$

$D_{k}, D_{r}, D_{s}$

$d, d^{\prime}$

$d_{i}$

$d_{\min }, d_{\max }$

$f_{d, c_{y}} \partial d \partial c_{y}$

$h$

$H_{k}, H_{c}$

$K_{v}$

$\mathrm{K}_{\mathrm{B}}$

$K_{\text {oy }}$

$\bar{K}_{\text {oy }}$

$k_{x}, k_{y}$

$L$

$N_{p}$ column cross sectional area, $\mathrm{m}^{2}$

coalescence constants

solute concentrations in the continuous and dispersed phases respectively, $\mathrm{kg} \cdot \mathrm{m}^{-3}$

as defined in Table $\mathbf{1}$

continuous and dispersed phases axial dispersion coefficients respectively, $\mathrm{m}^{2} \cdot \mathrm{s}^{-1}$

column, rotor and stator diameters respectively, $\mathrm{m}$

droplet diameter, $\mathrm{mm}$

characteristic droplet diameter in the ith partition, $\mathrm{mm}$

minimum and maximum droplet diameters, $\mathrm{mm}$

number of droplets having concentration $c_{y}$ and diameter $d$ in the range

$[d, d+\partial d] \times\left[c_{y}, c_{y}+\partial c_{y}\right]$

coalescence frequency $\mathrm{s}^{-1}$

column and single compartment heights respectively, $\mathrm{m}$

slowing factor

total specific throughput $\mathrm{m}^{3} \cdot \mathrm{m}^{2} \cdot \mathrm{s}^{-1}$

overall mass transfer coefficient, $\mathrm{m} \cdot \mathrm{s}^{-1}$

average overall mass transfer coefficient, $\mathrm{m} \cdot \mathrm{s}^{-1}$

continuous and dispersed phases individual mass transfer coefficients respectively, $\mathrm{m} \cdot \mathrm{s}$

number of external (spatial) coordinate cells number of partitions of the internal coordinate (pivots) 


\begin{tabular}{|c|c|}
\hline$N$ & rotor speed, rpm, $\mathrm{s}^{-1}$ \\
\hline$P_{r}$ & breakage probability \\
\hline$Q_{b o t}$ & $\begin{array}{l}\text { total flow rate at bottom of the column, } \\
\mathrm{m}^{3} \cdot \mathrm{s}^{-1}\end{array}$ \\
\hline$Q_{x, i n}, Q_{y, i n}$ & $\begin{array}{l}\text { continuous and dispersed phases inlet flow } \\
\text { rates, } \mathrm{m}^{3} \cdot \mathrm{s}^{-1}\end{array}$ \\
\hline$Q_{t o p}$ & $\begin{array}{l}\text { dispersed phase flow rate at top of the col- } \\
\text { umn, } \mathrm{m}^{3} . \mathrm{s}^{-1}\end{array}$ \\
\hline$t$ & time, $\mathrm{s}$ \\
\hline $\bar{u}_{x}$ & $\begin{array}{l}\text { continuous phase velocity relative to the } \\
\text { column walls, } \mathrm{m} \cdot \mathrm{s}^{-1}\end{array}$ \\
\hline $\bar{u}_{y}$ & $\begin{array}{l}\text { dispersed phase velocity relative to the col- } \\
\text { umn walls, } \mathrm{m} \cdot \mathrm{s}^{-1}\end{array}$ \\
\hline $\bar{u}_{r}$ & relative drop (slip) velocity, $\mathrm{m} \cdot \mathrm{s}^{-1}$ \\
\hline $\bar{u}_{t}$ & terminal droplet velocity, $\mathrm{m} \cdot \mathrm{s}^{-1}$ \\
\hline$v, v^{\prime}$ & droplet volumes, $\mathrm{m}^{3}$ \\
\hline$v_{\min }, v_{\max }$ & $\begin{array}{l}\text { minimum and maximum droplet volume, } \\
\mathrm{m}^{3}\end{array}$ \\
\hline$w_{i}$ & number concentration in the ith partition \\
\hline$z$ & spatial coordinate, $\mathrm{m}$ \\
\hline$z_{d}, z_{y}$ & dispersed feed inlet, $\mathrm{m}$ \\
\hline$z_{c}, z_{x}$ & continuous phase inlet, $\mathrm{m}$ \\
\hline$\alpha_{x}, \alpha_{y}$ & as defined in Table $\mathbf{A} 2$ \\
\hline$\beta_{n}$ & $\begin{array}{l}\text { daughter droplet distribution based on drop- } \\
\text { let number, } \mathrm{m}^{-1}\end{array}$ \\
\hline$\varepsilon$ & energy dissipation, $\mathrm{m}^{2} \cdot \mathrm{s}^{-3}$ \\
\hline$\varepsilon_{p}$ & machine epsilon \\
\hline$\gamma$ & phase ratio \\
\hline$\Gamma$ & droplet breakage frequency, $1 / \mathrm{s}$ \\
\hline$\lambda$ & coalescence efficiency \\
\hline$\phi_{x}, \phi_{y}$ & $\begin{array}{l}\text { continuous and dispersed phase hold up } \\
\text { respectively }\end{array}$ \\
\hline$\phi_{e}$ & $\begin{array}{l}\text { dispersed phase hold up entrained with the } \\
\text { continuous phase }\end{array}$ \\
\hline$\rho_{x}, \rho_{y}$ & $\begin{array}{l}\text { density of the continuous and dispersed } \\
\text { phases respectively, } \mathrm{kg} \cdot \mathrm{m}^{-3}\end{array}$ \\
\hline$\mu_{x}$ & $\begin{array}{l}\text { continuous phase viscosity, } \\
\mathrm{kg} \cdot \mathrm{m}^{-1} \cdot \mathrm{s}^{-1}\end{array}$ \\
\hline$\omega$ & coalescence frequency, $\mathrm{m}^{3} \cdot \mathrm{s}^{-1}$ \\
\hline$\omega_{R}, \omega_{R, c r i t}$ & $\begin{array}{l}\text { rotor and critical rotor speeds respectively, } \\
\mathrm{s}^{-1}\end{array}$ \\
\hline$\sigma$ & interfacial tension, $\mathrm{N} \cdot \mathrm{m}^{-1}$ \\
\hline$\theta$ & TVD parameter between 1 and 2 . \\
\hline$\vartheta\left(d^{\prime}\right)$ & $\begin{array}{l}\text { mean no. of daughter droplets produced } \\
\text { upon breakage of mother droplet of diame- } \\
\text { ter } d^{\prime} \text {. }\end{array}$ \\
\hline$\varsigma$ & time and space vector \\
\hline
\end{tabular}

\section{ACKNOWLEDGEMENTS}

The authors acknowledge the financial support from DFG (Deutsche Forschungsgemeinschaft), Bonn and DAAD (Deutscher Akademischer Austauschdienst), Bonn.

\section{APPENDIX}

\section{The LLECMOD Program}

The complete mathematical models described above are programmed using Visual Digital FORTRAN with optimized and efficient numerical algorithms. To facilitate the data input and output, a graphical user interface was designed. The graphical interface of the LLECMOD program is depicted in Fig. (A1). It shows the structure of the main input window and the sub-windows for the parameter input. The main window contains all correlations and operating conditions that can be selected using the drop down menus.

\section{USER INPUT DATA AND FUNCTIONS}

The above discrete formulation requires a grid structure input for both droplet diameter and column height: $d_{i} i=1$, $2, \ldots N_{p} ; z_{l}, l=1,2, \ldots L$; the breakage frequency function $\Gamma\left(d_{i}, \bar{c}_{y}, \phi_{y}\right)$; the coalescence frequency $\omega\left(d_{i}, d_{j}, \bar{c}_{y}, \phi_{y}\right)$, the axial dispersion coefficients for both phases: $\bar{D}_{y}\left(\bar{d}, \bar{c}_{y}, \phi_{y}\right)$, $\bar{D}_{x}\left(\bar{d}, \bar{c}_{y}, \phi_{y}\right)$, the individual mass transfer coefficients and the terminal droplet velocity: $u_{t}\left(d_{i}, \bar{c}_{y}, \phi_{y}\right)$. The data base of LLECMOD contains many popular correlations for these functions (see Tables below) and the flexibility of supplying any new correlation through a specially designed user modules written in FORTRAN90 format.

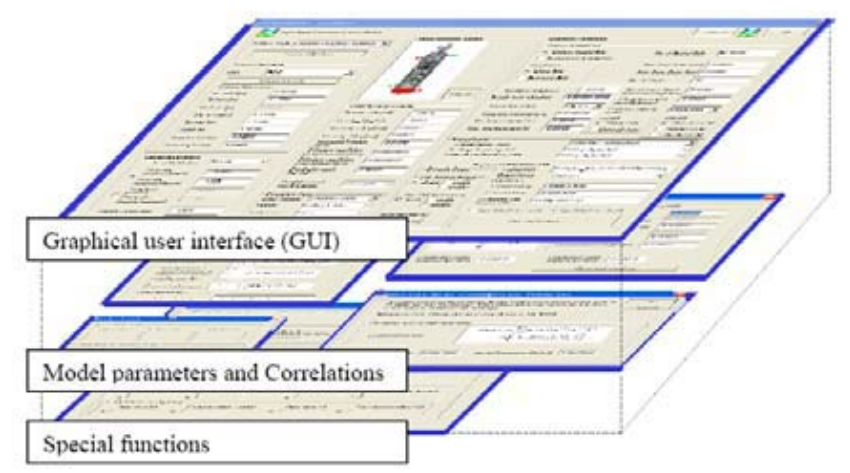

Fig. (A1). Input mask and graphical user interface.

The input window is structured in nine levels, where all simulation and input parameters can be selected and controlled. The coloured fields in Fig. (A2) mark the distinct input fields.

The input masks are saved in the FORTRAN90 workspace in the folder LLECMOD_DIALOG resources (see Fig. (A3)). This is a user file with all column specific data and operating conditions, and is stored as a TXT file in the folder UserInput with the filename Dialog-INPUT-OUTPUT. All changes, which are made in the input window, are stored simultaneously in the TXT file. The popular correlations for 


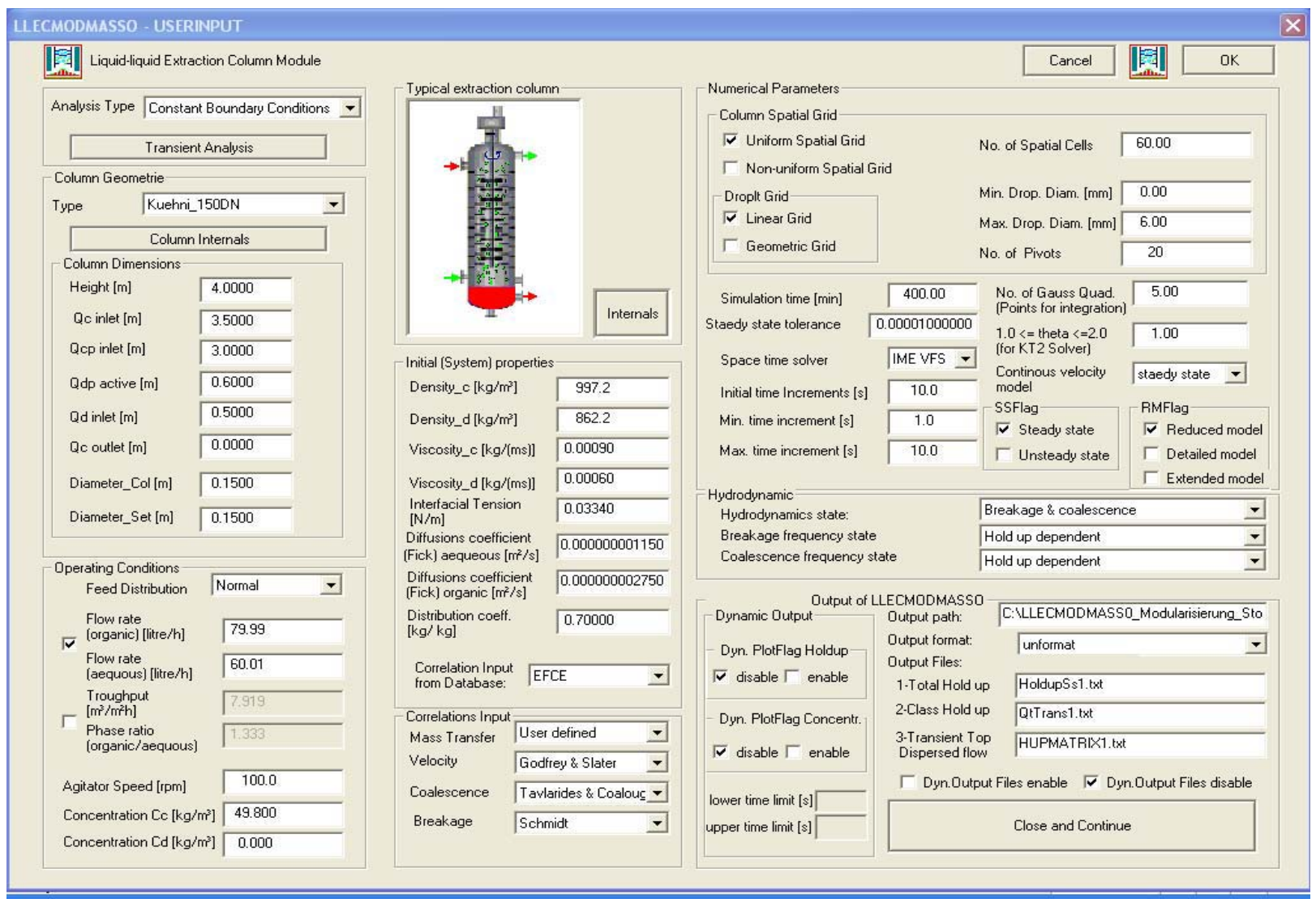

Fig. (A2). The main input dialog of the LLECMOD showing the input of the present sample problem.

terminal droplet velocity, breakage and coalescence frequencies and the individual mass transfer coefficients are given in the Tables.

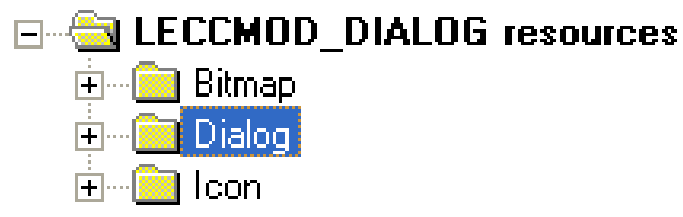

Fig. (A3). Home directory for the resource dialogs.

\section{COLUMN MODULES}

The spatially distributed population balance equation is general for any type of extraction column. However, what makes the equation specific is the internal geometry of the column as reflected by the required correlations for hydrodynamics and mass transfer. Accordingly, the correlation parameters that are now obtained based on single droplet and droplet swarm experiments, are considered in a modularized structure for the simulation program.

Thus, all column specific correlations are defined in the Userfunction file, which must be linked to the numeric solver algorithm. The solver algorithms are defined in a common folder including the Sources files and the column specific user functions, where the structure is shown in Fig. (A4).

The single modules can be attached easily to the program. All modules must be declared in the main program. This file is called a Maindriver, which contains all module- and file specific variable declarations. All column specific modules must be linked to the Maindriver file as shown in Fig. (A5). The input of column specific data is provided on a Windows based interface given in Fig. (A2). For each column model, the operating conditions such as throughput, inlet concentrations, rotational speed as well as geometric parameters can be specified. To facilitate the input of these data, the parameters input is realized directly in input frames containing a short description of the kind of parameter and an input field. The input fields contain the default parameters as initial values which could be easily changed by the user. An example for an RDC geometrical input dialog is shown in Fig. (A6).

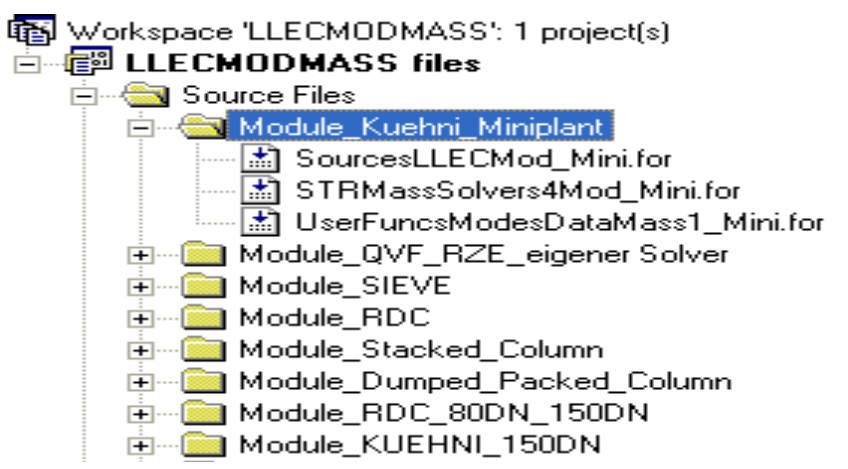

Fig. (A4). Modular structure of the program containing the source file, solver file and user function file for each column. 


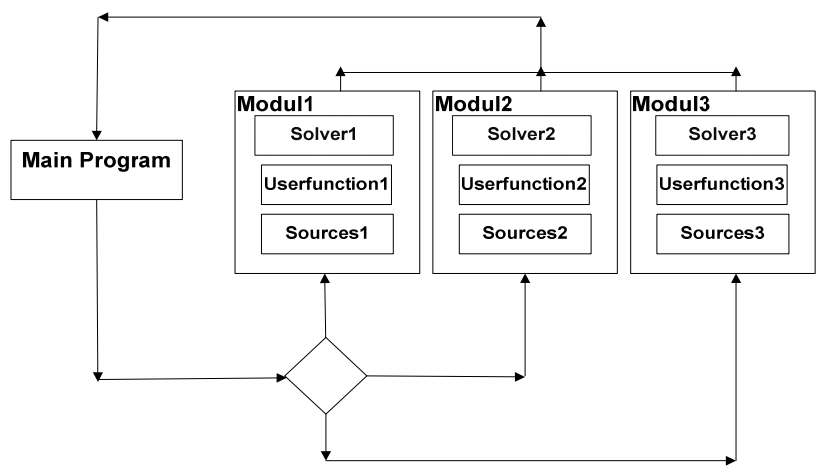

Fig. (A5). Modular structure of the simulation program.

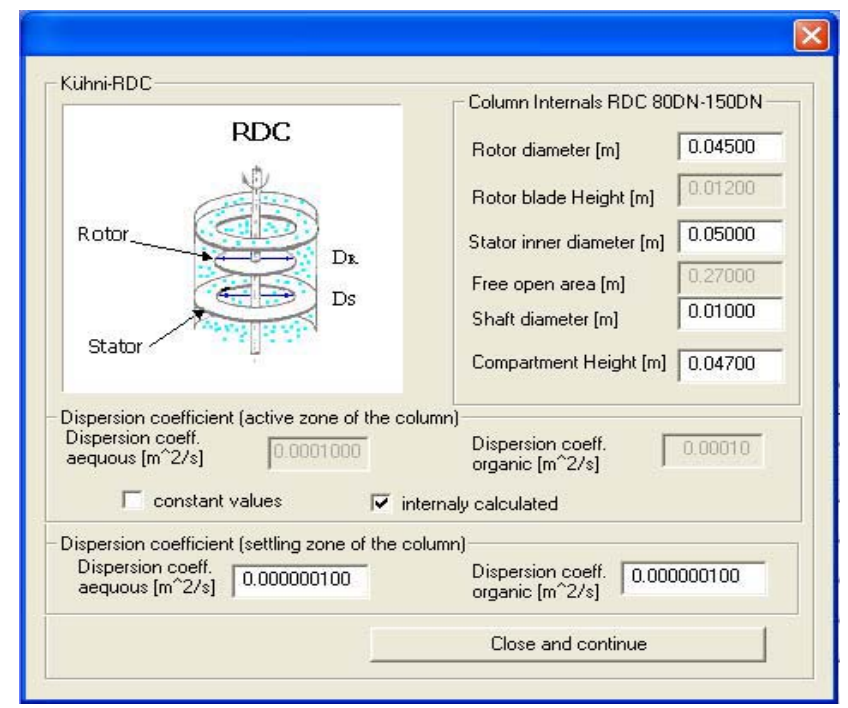

Fig. (A6). Input windows for the column specific geometric conditions.

\section{GRIDS GENERATION}

The spatial grid structure depends on the column geometry as shown in Fig. (A7) and on the minimum and maximum droplet diameters prevailing in the column. The program provides two types of grids for both spatial domain (column height) and droplet diameter. For droplet diameter geometric and uniform droplet discretizations are available. The geometric grid is useful when the sizes of the droplet diameters vary on a wide range and is given by:

$d_{i-1 / 2}=d_{\min }\left(\frac{d_{\max }}{d_{\min }}\right)^{\frac{i-1}{N_{p}}}, i=1,2 \ldots N_{p}+1$

For the column height a uniform grid structure of the form: $z_{l-1 / 2}=\Delta z(l-1), \quad l=1,2, \ldots L$ is used. However, the non-uniform grid structure is constructed by a combination of uniform grids to produce a relatively fine structure around the dispersed and continuous phase inlets, where permanent discontinuities appear. This provides a sharp resolution of these discontinuities at steady state conditions without excessive increase in the number of grid points. The numeric parameters can be selected as shown in Fig. (A7), where grid structure, discretization scheme and integration parameters can be changed.

\begin{tabular}{|c|c|c|c|}
\hline $\begin{array}{l}\text { Numerical Parameters } \\
\text { Column Spatial Grid }\end{array}$ & & \multirow{3}{*}{ No. of Spatial Cells } & \multirow{3}{*}{40.00} \\
\hline$\sqrt{\checkmark}$ Uniform Spatial Grid & & & \\
\hline$\Gamma$ Non-uniform Spatial & Grid & & \\
\hline Droplt Grid & & Min. Drop. Diam. [mm] & 0.00 \\
\hline$\sqrt{\checkmark}$ Linear Grid & & Max. Drop. Diam. [mm] & 6.00 \\
\hline$Г$ Geometric Grid & & No. of Pivots & 30 \\
\hline Simulation time [min] & 400.00 & $\begin{array}{l}\text { No. of Gauss Quad. } \\
\text { Points for integration }\end{array}$ & 5.00 \\
\hline Steady state tolerance & 0.00000100000 & $\begin{array}{l}1.0<=\text { theta }<=2.0 \\
\text { (for } \mathrm{KT} 2 \text { Solver) }\end{array}$ & 1.00 \\
\hline Space time solver & IME VFS - & \multirow{2}{*}{$\begin{array}{l}\text { Continous velocity } \\
\text { model }\end{array}$} & staedy state $\quad \nabla$ \\
\hline Initial time Increments [s] & 10.0 & & \multirow{3}{*}{$\begin{array}{l}\text {-RMFlag } \\
\nwarrow \checkmark \text { Reduced model } \\
\Gamma \text { Detailed model }\end{array}$} \\
\hline Min. time increment [s] & 1.0 & $\begin{array}{l}\text { SSFlag } \\
\sqrt{\nabla} \text { Steady state }\end{array}$ & \\
\hline Max. time increment [s] & 100.0 & Г Unsteady state & \\
\hline
\end{tabular}

Fig. (A7). Grid structure.

\section{DISPERSED AND CONTINUOUS PHASES CHEMICAL COMPONENTS}

The physical properties required for the evaluation of droplet transport and interactions (breakage and coalescence) as well as for mass transfer coefficients are loaded from a simple database containing the EFCE compounds [77] for the dispersed and continuous phases. However, the user could add the physical properties for any new chemical component by editing the files: LLECMOD $\backslash$ CompData. Otherwise, constant physical properties could be defined directly in the input dialog of Fig. (A8).

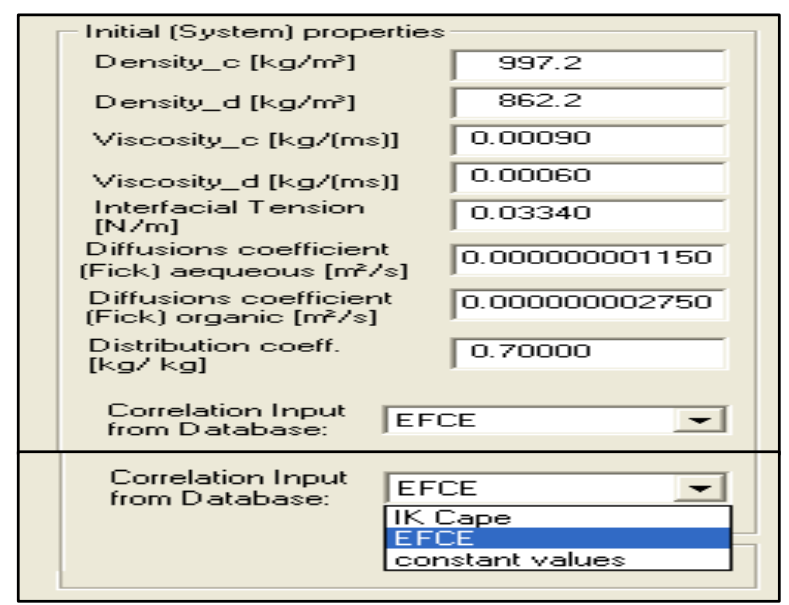

Fig. (A8). Input dialog of the chemical properties.

The dependences of the chemical properties on solute concentration are programmed in polynomial forms based on the EFCE correlations. The correlation constants are given in the folder $\backslash$ LLECMOD MASS0_Final $\backslash$ MatProp Lib which contains several ordinary chemical systems. Moreover, LLECMOD provides the data structure in the IK-Cape PPDX format, which can be implemented easily in the program.

The inlet feed distribution could be read directly from a user-defined file in tabulated form, where it is normalized internally according to the relation: 


$$
\varphi_{i}^{\text {feed }}=\frac{\overline{\varphi_{i}} \Delta d_{i}}{\sum_{i=1}^{M_{x}} \overline{\varphi_{i}} \Delta d_{i}}
$$

The second form of the feed input is based on three of the most frequently used distributions to fit the liquid-liquid distributors or droplet distributions in agitated columns; namely, the normal, log normal and Weibull distributions (see Fig. (A9)). A mono-dispersed distribution is also provided to allow correlation and numerical tests. For each distribution the parameters must be defined by typical distribution parameters such as mean and standard deviations.

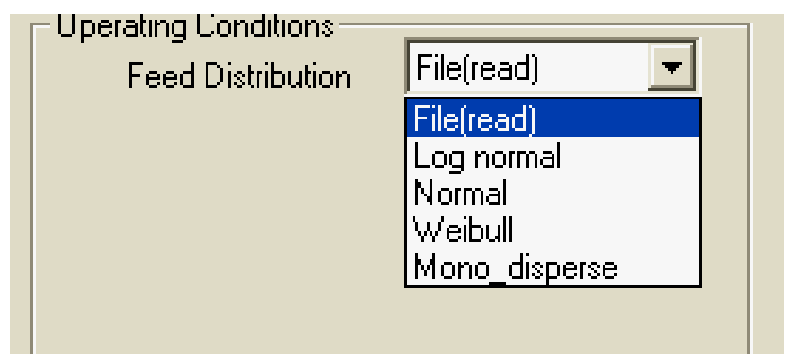

Fig. (A9). Feed inlet distribution.

The file read functionality provides a useful tool to import experimental evaluated distributions. The ASCII file only contains one column, where the droplet hold up in each partition is defined. The number of data entries must agree with the numbers of partitions $\left(N_{p}\right)$ selected in the main input window otherwise the program will display an error message and stop. Typical inlet distributions available are shown in Fig. (A10) for an average droplet size of $3 \mathrm{~mm}$.

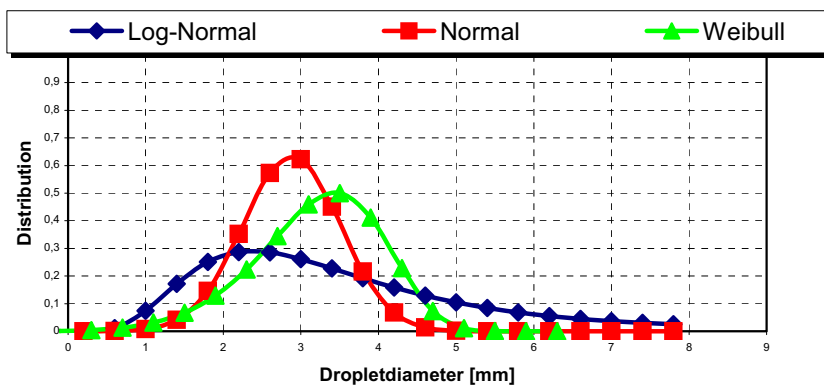

Fig. (A10). Typical inlet distributions using the default parameters.

\section{THE TERMINAL DROPLET VELOCITY}

The LLECMOD has several correlations for the terminal droplet velocity that can be chosen by the user as shown in Fig. (A11). These velocity correlations are: Klee and Treybal [45], Vignes [46], Grace [47], and the rigid sphere law interpolated between the viscous and inertial regimes [48].

Moreover, the correlation developed by Henschke [49] is also available, where the velocity model can be fitted to the experimental data. Typical values of the fitting parameters for the Henschke model are given in Fig. (A12). If the user does not choose any of these correlations, LLECMOD automatically chooses the suitable velocity correlation by default, based on the selection chart detailed in the book of Godfrey and Slater [2]. Moreover, if the user has a specific velocity law, it can be added to the user input module as a FORTRAN90 code. This droplet swarm effect may be taken into account in a form $\left(1-\phi_{y}\right)^{m}$ as can be found in Misek [55].

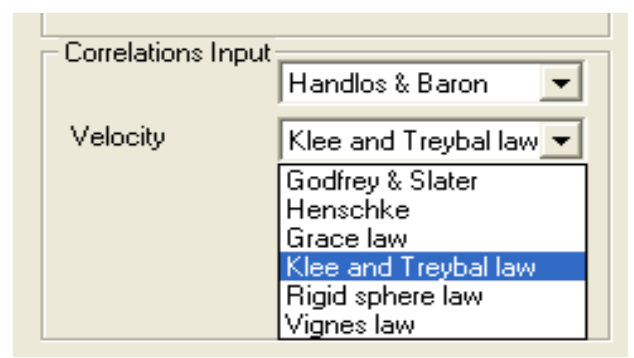

Fig. (A11). Selection of terminal velocity correlations.

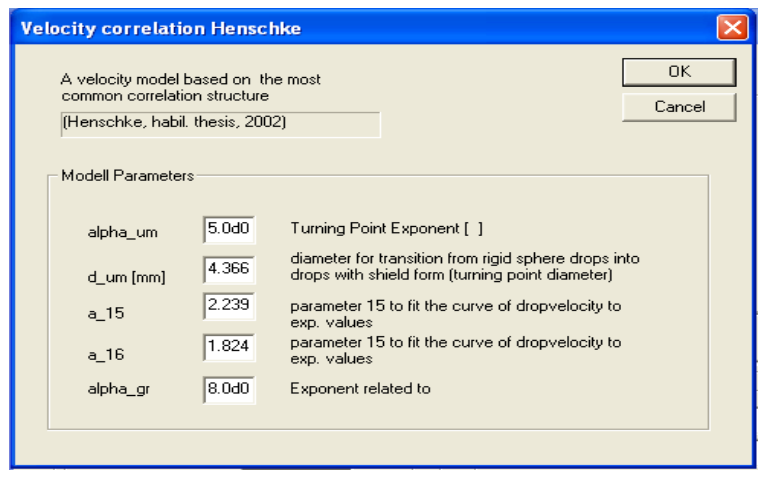

Fig. (A12). User defined parameter input for the Henschke model.

\section{CONTINUOUS PHASE VELOCITY MODELS}

The continuous phase velocity models required to calculate the dispersed phase velocity $\bar{u}_{y}$ are shown in Table $\mathbf{A 1}$. The first velocity model corresponds to the interface level control as shown in Fig. (A13). In this control scheme the outlet continuous flow rate is manipulated to control the position of the interface at the top of the column. The velocity model corresponding to this scheme shows an oscillatory behaviour in the dispersed phase hold-up as reported both experimentally by Hufnagl et al. [56] and theoretically by Weinstein et al. [14] and Attarakih et al. [19].

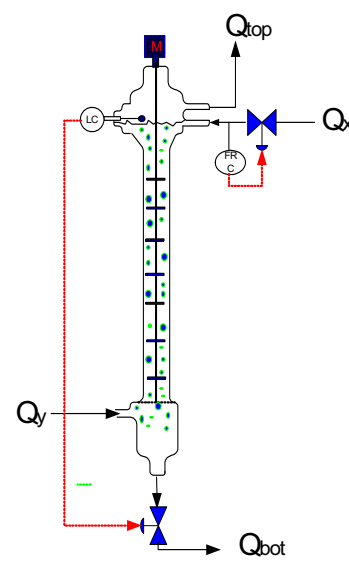

Oscillatory control scheme

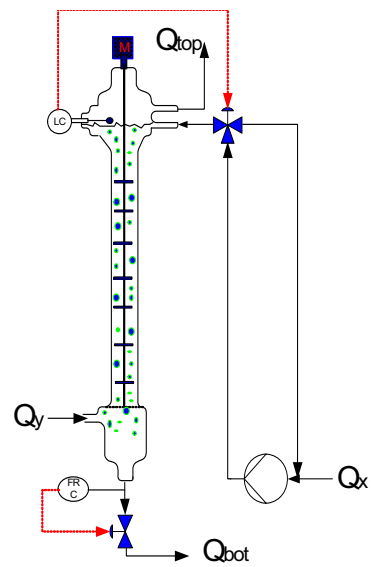

Non-oscillatory control scheme
Fig. (A13). Conventional and improved dispersed phase level control. 
Oscillatory [57]:

$$
\begin{array}{r}
\bar{u}_{x}=\frac{Q_{t o p}}{A_{c}}-\alpha_{x} \frac{Q_{x, i n}}{A_{c}}-\alpha_{y} \frac{Q_{y, i n}}{A_{c}}-\int_{d_{\min }}^{d_{\max }} v(d) u_{r}(d, \phi, \boldsymbol{P}) f_{d}(d ; z, t) \partial d \\
Q_{t o p}=\int_{d_{\min }}^{d_{\max }} v(d) u_{r}(d ; \phi(H, t), \boldsymbol{P}) f_{d}(d ; Z, t) \partial d
\end{array}
$$

Steady state [58]:

$$
\bar{u}_{x}=\alpha_{x} \frac{Q_{x, i n}}{A_{c}(1-\phi)}+\frac{\bar{D}_{x}}{1-\phi} \frac{\partial \phi}{\partial z}
$$

Non-oscillatory [19]:

$$
\begin{gathered}
\bar{u}_{x}=\frac{Q_{\text {top }}}{A_{c}}-\alpha_{c} \frac{Q_{x, i n}}{A_{c}}-\alpha_{d} \frac{Q_{y, i n}}{A_{c}}-\int_{d_{\min }}^{d_{\max }} v(d) u_{r}(d, \phi, \boldsymbol{P}) f_{d}(d ; z, t) \partial d \\
Q_{x, \text { in }}+Q_{y}=Q_{\text {top }}+Q_{b o t} \\
Q_{x, \text { out }}=\left(1-\phi_{e}\right) Q_{b o t}
\end{gathered}
$$

The second velocity model assumes that the continuous phase is at a steady state and, hence, it is not applicable for transient simulations, while the third velocity model is based on the control scheme shown in Fig. (A13) by adjusting the flow rate of the incoming continuous phase.

The oscillation in the dispersed phase hold-up could be explained as follows. At the instant of introducing the dispersed phase at bottom of the column, the outlet flow rate of the continuous phase increases immediately because it is displaced by the dispersed phase $\left(\phi_{x}+\phi_{y}=1\right)$, at the same time the dispersed phase hold-up is propagated along the column (due to the hyperbolic nature of the model) causing an increase in the top flow rate, $Q_{t o p}$.

At the bottom of the column and according to the first velocity model (shown in Table A1), $Q_{x, \text { out }}=A_{c} \bar{u}_{x}$ starts to decrease to satisfy the total volume balance. As a result this reduction in the continuous phase flow rate at the bottom of the column will decrease the dispersed phase hold-up according to $\bar{u}_{y}=\bar{u}_{r}-\bar{u}_{x}$.

Table A2. Axial Dispersion Coefficient Correlations for RDC and Kühni Columns

$$
\begin{aligned}
& \text { Kühni-DN-80 DN-150 [59,60]: } \\
& \bar{D}_{x}=0.42+0.29\left(\frac{\bar{u}_{y}}{\bar{u}_{x}}\right)+\left[0.01126\left(\frac{N D_{r}}{\bar{u}_{x}}\right)+\frac{13.38}{3.18+\left(\frac{N D_{R}}{\bar{u}_{x}}\right)}\right]\left(\frac{\bar{u}_{x} D_{R} \rho_{x}}{\mu_{x}}\right)^{-0.08}\left(\frac{D_{k}}{D_{R}}\right)^{0.16}\left(\frac{D_{k}}{H_{C}}\right)^{0.1}\left(\frac{D_{s}}{D_{k}}\right)^{2} \\
& \bar{D}_{y}=0.0027+2.48 \cdot 10^{-6} \cdot \mathrm{Re}^{1.2} \cdot d \cdot \bar{u}_{r} \cdot\left(\frac{\rho_{x}}{\mu_{x}}\right)^{-1.9} \cdot \bar{u}_{r} \cdot H_{c} \\
& \text { RDC-DN-80 DN-150[60,61]: } \\
& \bar{D}_{x}=\left(0.00138+8.26 \cdot 10^{-7}\left(\frac{N \cdot D_{R}}{\bar{u}_{r}}\right)^{3.3} \bar{u}_{r}\right. \\
& \bar{D}_{x}=0.5+0.11\left(\frac{D_{k}}{H_{c}}\right)^{0.33}\left(\frac{D_{S}}{D_{K}}\right)^{2} \frac{\left(N D_{R}^{2} \rho_{x} / \mu_{x}\right.}{u_{x} D_{K} \rho_{x} / \mu_{x}} \\
& \bar{u}_{x} H_{c} \\
& \quad \text { with } \alpha_{x}=\left\{\begin{array}{l}
1, \quad z \leq z_{c} \\
0, \quad z>z_{c}
\end{array} \quad \begin{array}{ll}
1, & z \leq z_{d} \\
0, & z>z_{d}
\end{array}\right.
\end{aligned}
$$




\section{- Correlations Input} Mass Transfer

\begin{tabular}{|l|}
\hline Handlos \& Baron \\
\hline Handlos \& Baron \\
\hline Kumar \& Hartland \\
Wolschner \\
Slater \\
Korschinsky \\
Newman \\
Konig \& Brink \\
User defined \\
\hline
\end{tabular}

Fig. (A14). Mass transfer correlations available in the LLECMOD.

Accordingly, this decrease in the dispersed phase hold-up will propagate along the column and hence causing the top flow to decrease. This causes the continuous flow rate at the bottom to increase and, hence, the dispersed phase hold-up will increase again and the process repeats itself with de- creasing amplitude that is damped when the steady state is approached.

The non-oscillatory velocity model gets rid of this resonance behaviour by keeping the continuous phase flow rate at the bottom of the column at a constant value and, hence, it allows the inlet flow rate to vary according to:

$$
Q_{x, \text { in }}=Q_{\text {top }}+\frac{1}{1-\phi_{e}} Q_{x, o u t}-Q_{y}
$$

This is found to completely eliminate the oscillatory behaviour of the dispersed phase hold up since its magnitude at the base of the column is maintained constant.

\section{AXIAL DISPERSION COEFFICIENTS}

The axial dispersion coefficients, $\bar{D}_{x}$ and $\bar{D}_{y}$ for the dispersed and continuous phases are defined in the user input module as functions $D_{c}$ and $D_{d}$ using FORTRAN90. These coefficients are allowed to vary with the column height in

Table A3. Mass Transfer Correlations (Inside Droplets)

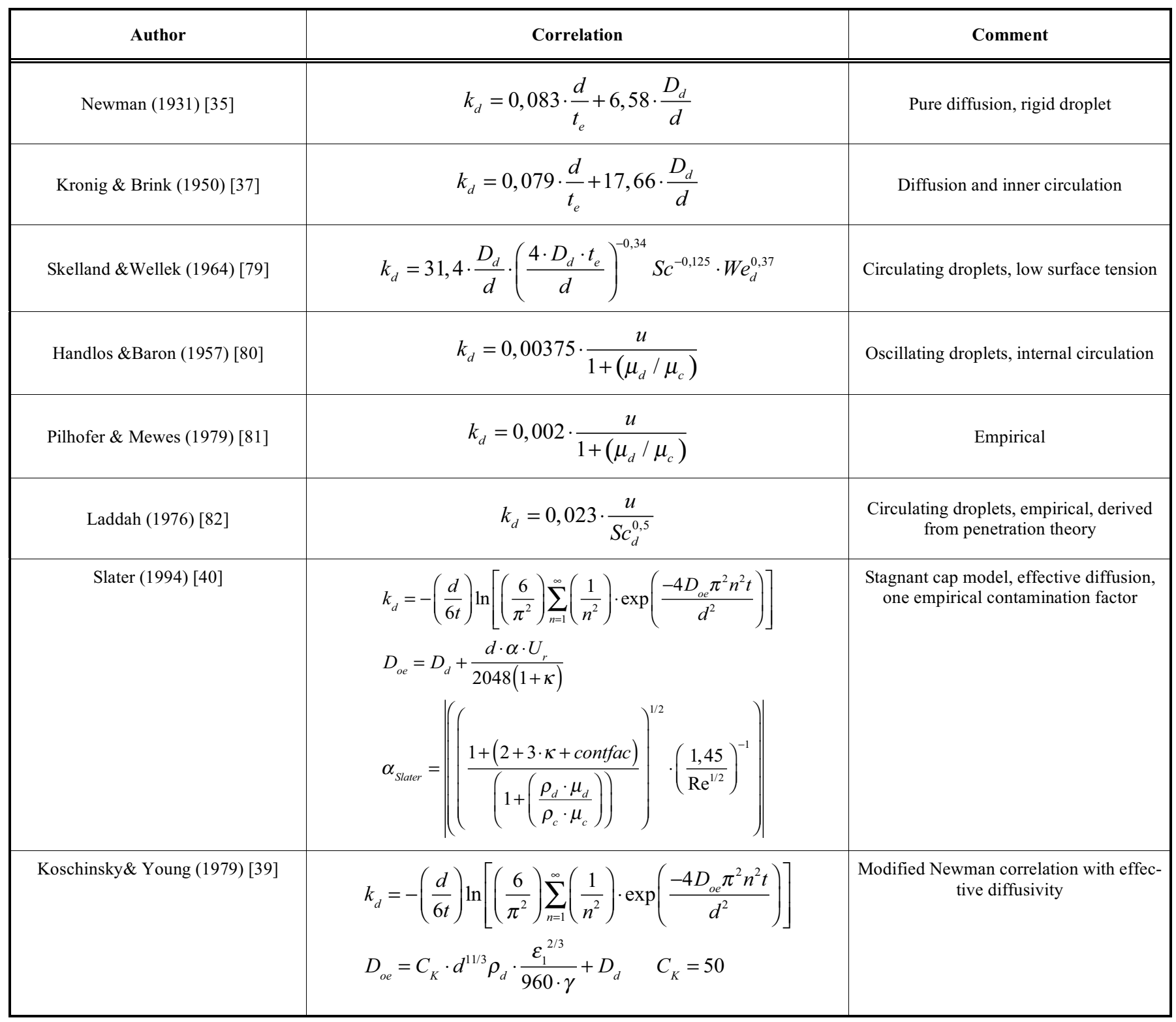


Table A4. Mass Transfer Correlations (Outside Droplets)

\begin{tabular}{|c|c|c|}
\hline Author & Correlation & Comment \\
\hline \hline Garner \& Tayeban (1960) [83] & $k_{c}=\frac{D_{c}}{d} \cdot\left(2+0,67 \sqrt{\mathrm{Re}_{p} \cdot S c}\right)$ & Rigid dropled \\
\hline Kronig \& Brink (1950) [37] & $k_{c}=\frac{D_{c}}{d} \cdot\left(0,6 \sqrt{\mathrm{Re}_{p} \cdot S c}\right)$ & Circulating droplet \\
\hline Treybal (1963) [84] & $k_{c}=\frac{D_{c}}{d} \cdot\left(0,725 \mathrm{Re}_{p}^{0,57} \cdot S c_{c}^{0,42}\left(1-\phi_{d}\right)\right)$ & Circulating droplet in swarm \\
\hline Clift et al. (1978) [85] & $\left.k_{c}=1,2 \cdot D_{c}^{0,5}\left[\frac{48 \sigma}{\pi^{2} d^{3}\left(2 \rho_{c}+3 \rho_{d}\right.}\right)\right]$ & Oscillating droplet \\
\hline Heertjes (1954) [86] & $k_{c}^{0,25}=0,83 \cdot \sqrt{\frac{D_{c} \cdot u_{r}}{d}}$ & Oscillating droplet \\
\hline Slater (1994) [87] & $k_{c}=\frac{D_{c}}{d} \frac{2}{\pi^{1 / 2}} \cdot \sqrt{\alpha_{\text {Slater }} \sqrt{P e}}$ & One empirical contamination factor \\
\hline
\end{tabular}

the present version of LLECMOD. Typical correlations from literature used in the LLECMOD program are given in Table A2.

\section{Mass-Transfer}

The mass transfer fluxes in the LLECMOD program are calculated based on the two-film theory, where the individual mass transfer coefficients are defined separately for the continuous $\left(k_{x}\right)$ and the dispersed $\left(k_{y}\right)$ phases. The correlations available for the individual mass transfer coefficients are shown in Fig. (A14) and Tables A3 and A4. In the simulation of liquid-liquid extraction columns with standard chemical systems, the Newman [35] or Handlos and Baron [36] models could be chosen. In some cases were no solid theoretical models are available (e.g. reactive extraction or very slow kinetics) the recently developed correlations can also be selected (the Wolschner [38], Bart [41], Korchinski \& Young [39], Kroning \& Brink [37], Slater [40] or the User defined model).

The mass transfer models account generally for deforming droplet inter-phases, where droplet circulation and oscillation can occur affecting the mass transfer performance. Thus, the mass transfer coefficients are drop-size dependent in the user-defined models to take into account inner circulation, surfactants and the rising velocity. The input dialog for the mass transfer user-defined model is shown in Fig. (A15).

In this dialog window the model parameters can be modified to fit the experimental data. The default values of the correlations are taken from the published literature, and the selection of the correct droplet state is guided by referring to Gourdon et al. [33].

\section{BREAKAGE FREQUENCY AND DAUGHTER DROPLET DISTRIBUTION}

The breakage frequency function $\Gamma\left(d, \overline{c_{y}}, \phi_{y}\right)$ can be easily defined in the user input module using FORTRAN90

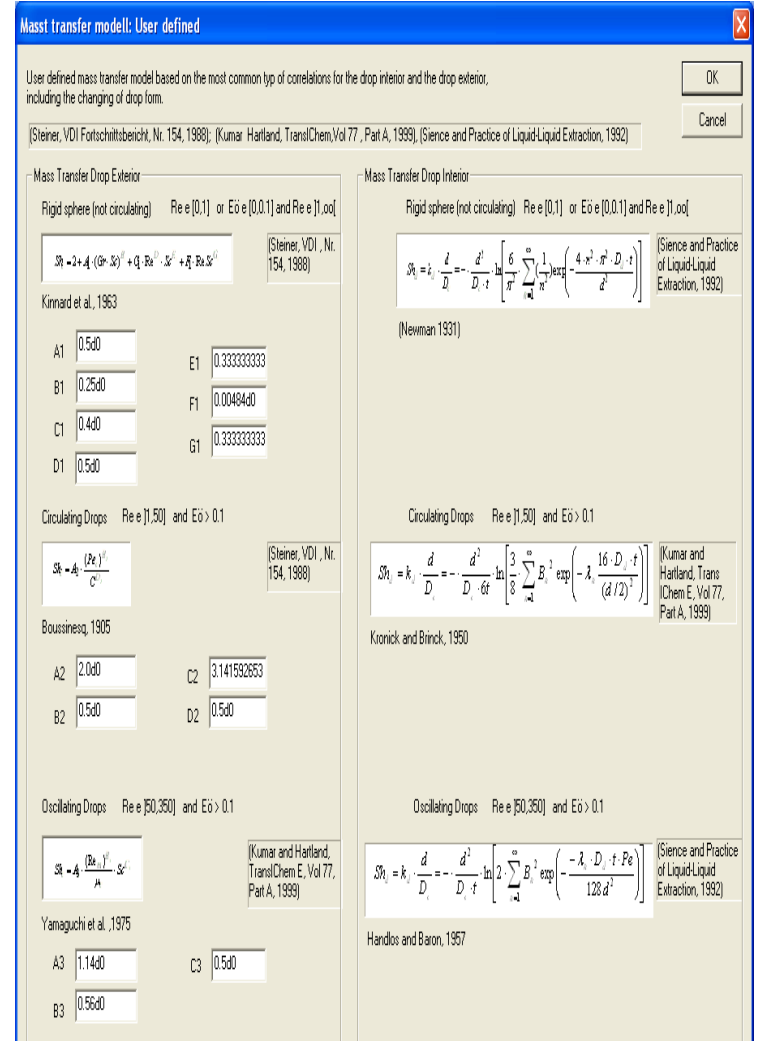

Fig. (A15). Input dialog for the user defined model taking different droplet states into account.

format. In case that the breakage frequency is independent of the dispersed phase hold up or the dispersed phase velocity it is called separable; that is, $\Gamma=\Gamma\left(d, \bar{c}_{y}\right)$. In this case, choose from the input menu: Breakage frequency state/Hold up independent, which is the default. On the other hand, if $\Gamma\left(d, \bar{c}_{y}, \phi_{y}\right)$, choose: Breakage frequency state/Hold-up de- 
pendent. The existing data base of LLECMOD contains five breakage frequency models. The correlations are different in the number of fitting parameters and mathematical complexity. For a general investigation of column behaviour, the correlations of Schmidt [26], Modes [62] and Steinmetz [27] are recommended.

The default parameters of the other correlations were taken from the published literature. Note that most of the correlations were developed for stirred vessels and not for extraction columns (e.g. Coulaloglou \& Tavlarides [11] and Laso [52]. So, the parameters in these correlations have to be refitted (for a given case) to match the experimental data. The correlations from Laso et al. [52] and Narsimhan and Ramkrishna [53] are strictly empirical, whereas the models from Coulaloglou and Tavlarides [11] and Tsouris and Tavlarides [64] are derived according to a phenomenological base. The correlation parameters for breakage frequency correlations employed in RDC and Kühni columns are given in Table A5. The parameter input dialog for the model of Coulaloglou and Tavlarides [11] is shown in Fig. (A16).

Table A5. Breakage Correlation Parameters [26,62]

\begin{tabular}{|c|c|c|c|c|c|}
\hline & $f_{1}$ & $f_{2}$ & $f_{3}$ & $f_{4}$ & $f_{5}$ \\
\hline \hline $\begin{array}{c}\text { RDC, } \\
\text { DN 150 }\end{array}$ & $1.310^{-06}$ & 0.33 & 2.78 & 0.016 & 0.127 \\
\hline $\begin{array}{c}\text { Kühni, } \\
\text { DN 80,150 }\end{array}$ & $1.210^{-03}$ & 0.476 & 2.58 & 0.136 & 0.028 \\
\hline
\end{tabular}

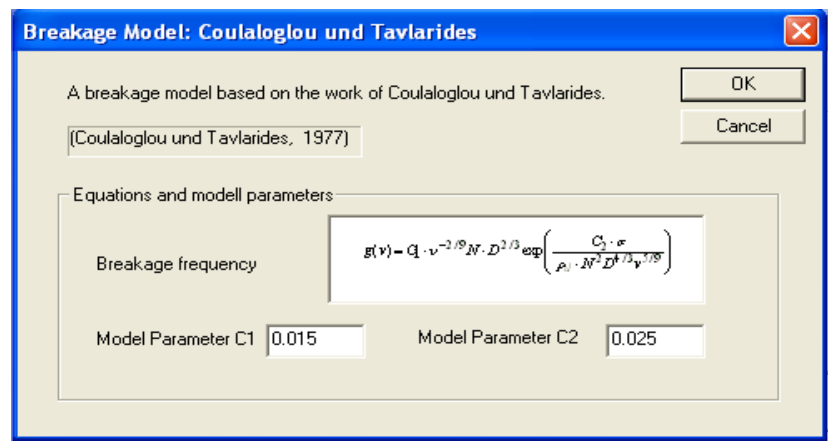

Fig. (A16). Input dialog for the model of Coulaloglou and Tavlarides [11].

\section{THE COALESCENCE FREQUENCY}

The coalescence frequency function $\omega\left(d, d^{\prime}, \bar{c}_{y}, \phi_{y}\right)$ is defined in the user input module using FORTRAN90. For the case that the coalescence frequency is independent of the dispersed phase hold-up, it is called separable; that is, $\omega\left(d, d^{\prime}, \bar{c}_{y}\right)$. In this case we choose from the input menu: coalescence frequency state/Hold up independent, which is the default. On the other hand, if $\omega=\omega\left(d, d^{\prime}, \bar{c}_{y}, \phi_{y}\right)$ choose: coalescence frequency state/hold up dependent.

The coalescence frequency can be estimated using four different coalescence models available in the literature (see Fig. (A17)). The models: Coulaloglou \& Tavlarides [11], Sovova [51], Tsouris \& Tavlarides [64] are developed based on a phenomenological approach and the model of Laso et al. [52] is strictly empirical. The phenomenological models are based on the film drainage theory using the statistic collision rate and the coalescence efficiency:

$\omega\left(d_{i}, d_{j}\right)=h\left(d_{i}, d_{j}\right) \cdot \lambda\left(d_{i}, d_{j}\right)$

The model of Sovova [51] consists of an additional energy term to account for the boundary interfacial energy. The model of the coalescence efficiency $h\left(d, d^{\prime}\right)$ between two droplets is an analogue to the stochastic collision probability of two gas molecules as defined in the kinetic theory of gases. The collision frequency is dependent on the film drainage time and impulse exchange between two colliding droplets.

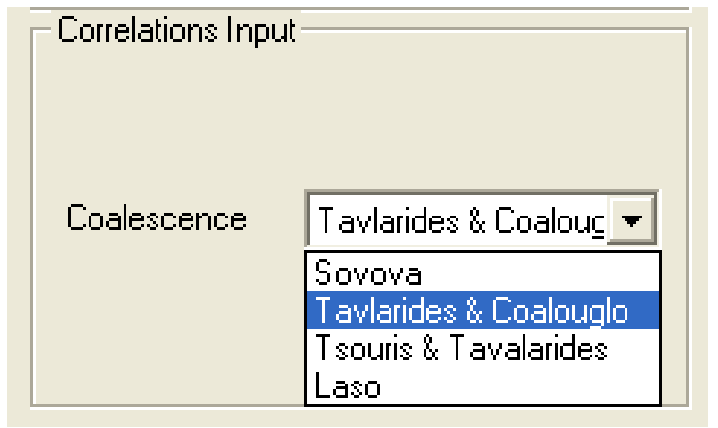

Fig. (A17). Coalescence models in the LLECMOD.

The application of coalescence parameters from the published literature is restricted to the definition of droplets size in the given equation. This is why some of the derivations of the coalescence rate equations are formulated in terms of the droplet volume rather than diameter. In the model of Colaloglou and Tavlarides [11] the parameters $\mathrm{C}_{3}$ and $\mathrm{C}_{4}$ values can be determined from column experiments and inserted in the marked fields in the dialog box shown in Fig. (A18).

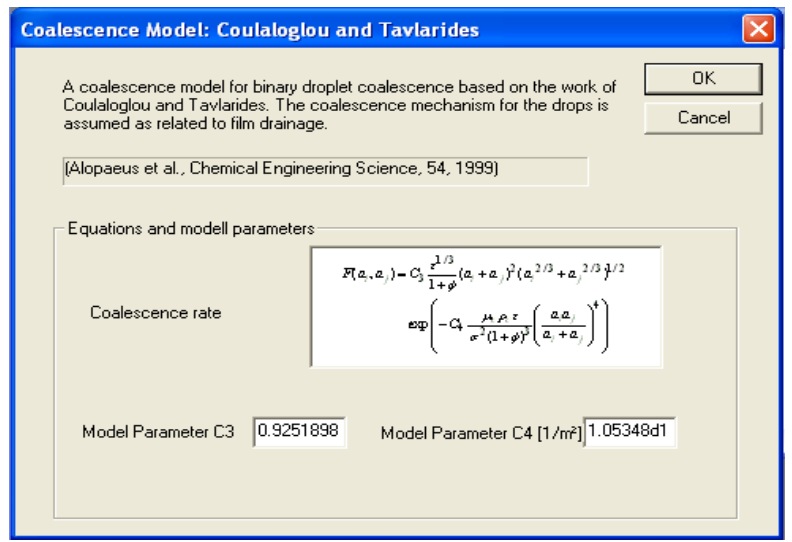

Fig. (A18). Dialog box for coalescence rate based on the model of Coulaloglou \& Tavlarides [11].

The typical values of the constants $C_{3}$ and $C_{4}$ published in the literature are given in Table A6. Note that the constants are determined in stirred vessels for test systems without mass transfer. In column simulations the approach of Coulaloglou and Tavlarides [11] is more often used than the other models. Despite its two fitting parameters, the model 
provides an easy fitting equation if the parameter optimization program is used. Fig. (A19) shows the dialog box of the parameter input for the model of Sovova [51].

Table A6. Coalescence Constants After Tsouris \& Tavlarides [17] Refitted by Alopaeus et al. [65]

\begin{tabular}{|c|c|c|}
\hline Author & $C_{3}$ & $C_{4}\left[\mathbf{m}^{-2}\right]$ \\
\hline \hline Hsia \& Tavlarides [63] & $4.5 \cdot 10^{-4}$ & $1.89 \cdot 10^{13}$ \\
\hline Tsouris \& Tavlarides [17] & $2.17 \cdot 10^{-4}$ & $2.28 \cdot 10^{13}$ \\
\hline Ross et al. [66] & $2.17 \cdot 10^{-4}$ & $3.0 \cdot 10^{13}$ \\
\hline Bapat \&Tavlarides [67] & $1.9 \cdot 10^{-4}$ & $2.0 \cdot 10^{-4}$ \\
\hline
\end{tabular}

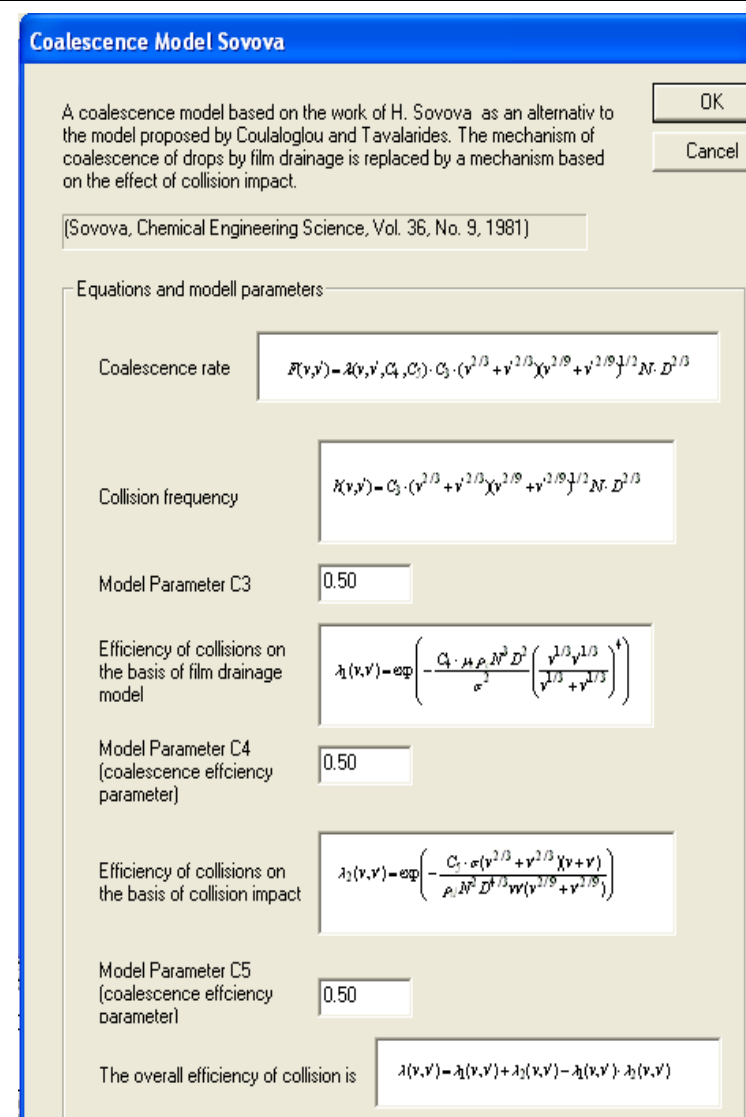

Fig. (A19). Input dialog for the coalescence model of Sovova [51].

The model of Sovova [51] (see Fig. (A19)) consists of three independent parameters $C_{3}, C_{4}$ and $C_{5}$. The model is derived with volume as the droplet characteristic size as a product of collision efficiency $(\lambda)$ and frequency $(h)$ :

$$
\begin{aligned}
\lambda\left(v, v^{\prime}\right) & =\lambda_{1}\left(v, v^{\prime}\right)+\lambda_{2}\left(v, v^{\prime}\right) \\
& -\lambda_{1}\left(v, v^{\prime}\right) \cdot \lambda_{2}\left(v, v^{\prime}\right) \\
h\left(v, v^{\prime}\right) & =C_{3}\left(v^{2 / 3}+v^{\prime 2 / 3}\right)\left(v^{2 / 9}\right. \\
& \left.+v^{\prime 2 / 9}\right)^{1 / 2} N D_{R}{ }^{2 / 3}
\end{aligned}
$$

Tsouris \& Tavlarides [17] (see Fig. (A20)) used a theoretical approach taking into account the turbulence flow field in the column compartment. Due to turbulent motion of eddies at different scales, the collision frequency was modelled based on a phenomenological approach without any parameter fitting. On the other hand, the coalescence efficiency contains one fitting parameter.

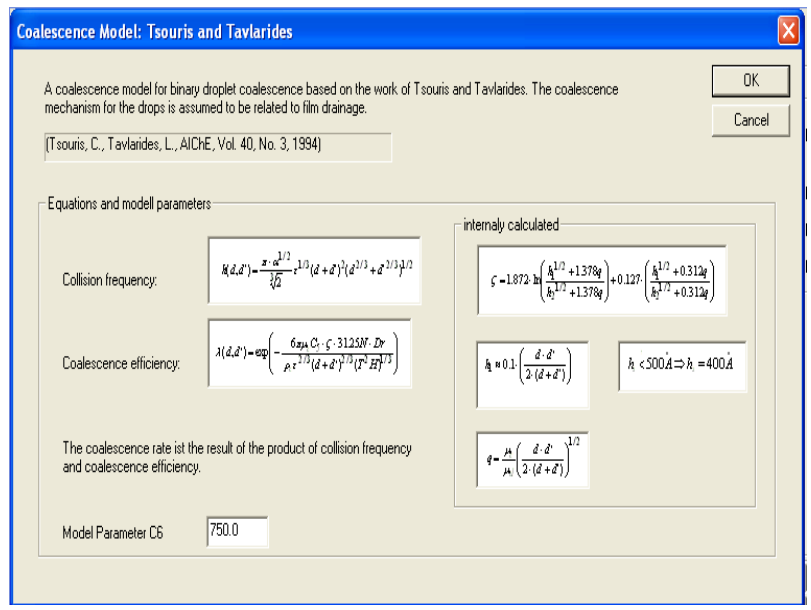

Fig. (A20). Coalescence model of Tsouris and Tavlarides [17] with one parameter.

\section{DROPLET PHASE SPACE-TIME SOLVERS}

The LLECMOD provides three droplet phase space-time solvers to discretize droplet diameter, column height and time as shown in Table A7 [19]. The user can choose from the drop-down menu provided by the input dialogue, the suitable solver with IMEFVS (IMplicit Euler Flux Vector Splitting) as the default one. In the present version, only the IME FVS solver is available for the numerical solution of model equations for mass transfer operations. The IME KT2 solver based on non-oscillatory central difference schemes to avoid eigenvalue decomposition required by high order upwind schemes is used for spatial discretization of the PBE given by Eq. (11).

Table A7. Available Phase Space-Time Solvers in LLECMOD

\begin{tabular}{|l|l|l|}
\hline Solver & Order & Description \\
\hline \hline $\begin{array}{l}\text { IME } \\
\text { FVS }\end{array}$ & $\begin{array}{l}\text { First order in } \\
\text { time and space }\end{array}$ & $\begin{array}{l}\text { Upwind differencing with flux vector } \\
\text { splitting with implicit Euler method. } \\
\text { Only the IME FVS solver can be used } \\
\text { for mass transfer operations. }\end{array}$ \\
\hline $\begin{array}{l}\text { IME } \\
\text { KT1 }\end{array}$ & $\begin{array}{l}\text { First order in } \\
\text { time and space }\end{array}$ & $\begin{array}{l}\text { Non-oscillatory central differencing } \\
\text { with implicit Euler method. }\end{array}$ \\
\hline KT2 & $\begin{array}{l}\text { First order in } \\
\text { time and second } \\
\text { order in space }\end{array}$ & $\begin{array}{l}\text { Non-oscillatory central differencing } \\
\text { scheme with implicit Euler method. }\end{array}$ \\
\hline
\end{tabular}

This solver uses a minmod numerical flux limiter to avoid undesirable spurious oscillations near discontinuity or sharp fronts [44]. This limiter uses a TVD (total variation diminishing) parameter $(\theta)$ for IME KT2 solver that can be chosen by the user from the input dialog. The value of the 
TVD parameter ranges from 1 to 2 with value 2 for the least dissipative behaviour while the value 1 guarantees a nonoscillatory scheme The minimum and maximum time steps, the final simulation time, the steady state tolerance can all be adjusted through the user input dialog. The reduced or detailed models (based on Eqs.(12) or (19) respectively) can also be selected.

\section{TRANSIENT SIMULATION}

Using the LLECMOD program, the transient column behaviour can be investigated numerically. To analyze the dynamic behaviour of the column, step-changes can be applied to the inlet variables to get the dynamic step response of the model. In the transient module, the following step changes can be applied:

- Inlet solute concentration in the dispersed phase, $C_{y, i n}$.

- Inlet solute concentration in the continuous phase, $C_{x, i n}$.

- Rotor rotational speed, $N$.

- Volumetric flow-rate of the dispersed phase, $Q_{y, i n}$.

- Volumetric flow-rate of the continuous phase, $Q_{x, i n}$.

The response of the outlet variables (dispersed phase hold up, solute concentration in both phases, Sauter mean droplet diameter and droplet size distribution) are plotted as function of time and column height.

The transient analysis dialog supplies two types of time step changes: simple step changed and two combined step changes (multi-step) as shown in Fig. (A21). In the second transient analysis dialog box shown in Fig. (A22), the magnitude of the step changes in the input variables can be specified in the dialog of Fig. (A22) and the response of the output variables will be written continuously to a user specified files.

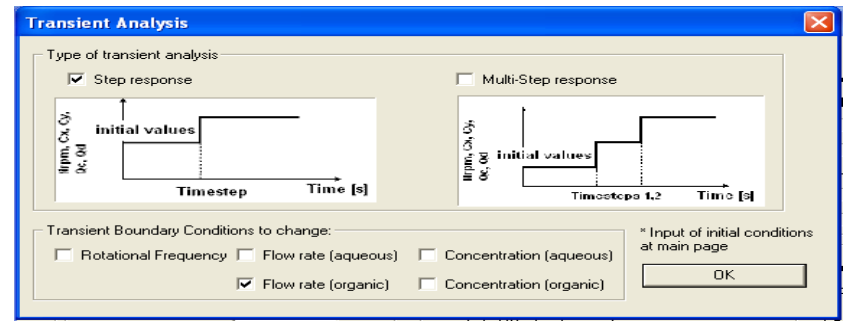

Fig. (A21). Step and multi-step changes in the input variables.

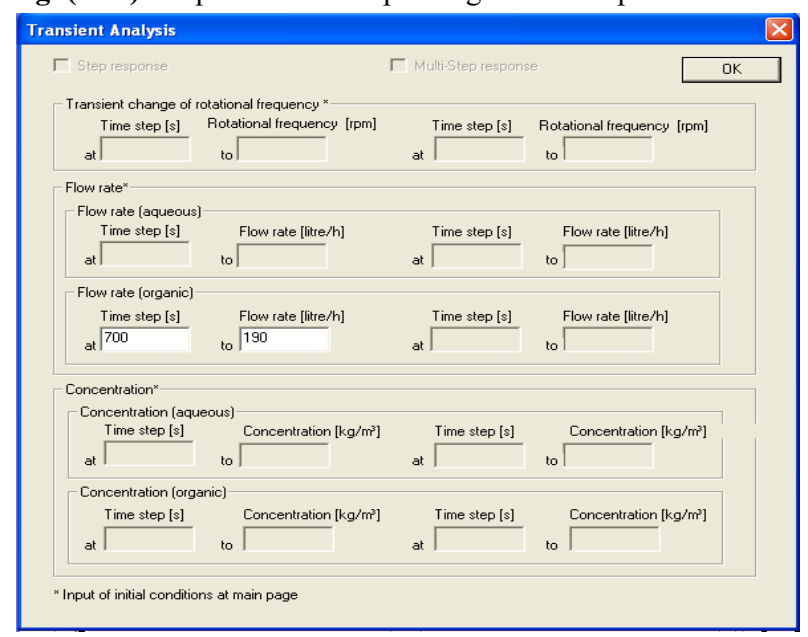

Fig. (A22). Input dialog for transient column analysis.

\section{COLUMN VARIABLES INPUT DIALOG}

The operating conditions of the column and its geometry (see Fig. (A23)) can be defined in the section "Column Operating conditions" defined in Table $\mathbf{A 8}$ and the corresponding dialog is shown in Fig. (A24).
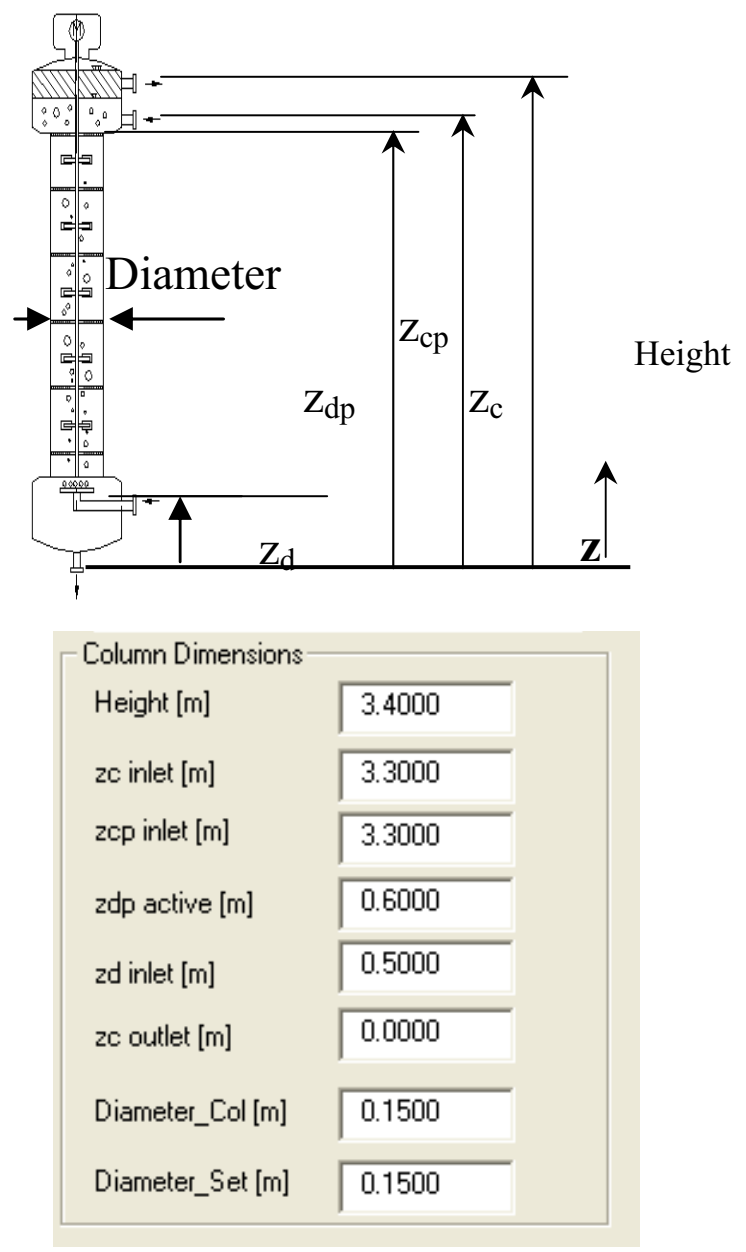

Fig. (A23). Column dimensions and flows.

\section{THE LLECMOD OUTPUT}

The output from the LLECMOD is of two types: the first one is graphical output consisting of the most important simulation results. These are the inlet feed distribution, the relative droplet velocity taking into account the slowing factor $K_{v}$, the hold-up along the column, the mean droplet diameter (Sauter diameter) and the droplet volume distribution at selected positions along the column. The second output is written to a predefined text files described in Table A9.

\section{LLECMOD GRAPHICAL OUTPUT}

The results of simulation from LLECMOD can be written to a series of text files defined in the output dialog shown in Fig. (A25). For graphical visualisation of the results, the following options can be selected:

- Plotting the results using the Compaq Array Visualizer.

- Plotting the results by running the MATLAB m-file (PlotHydrodynamics.m) in the directory Output 1 plot. 
Table A8. Column Input Variables

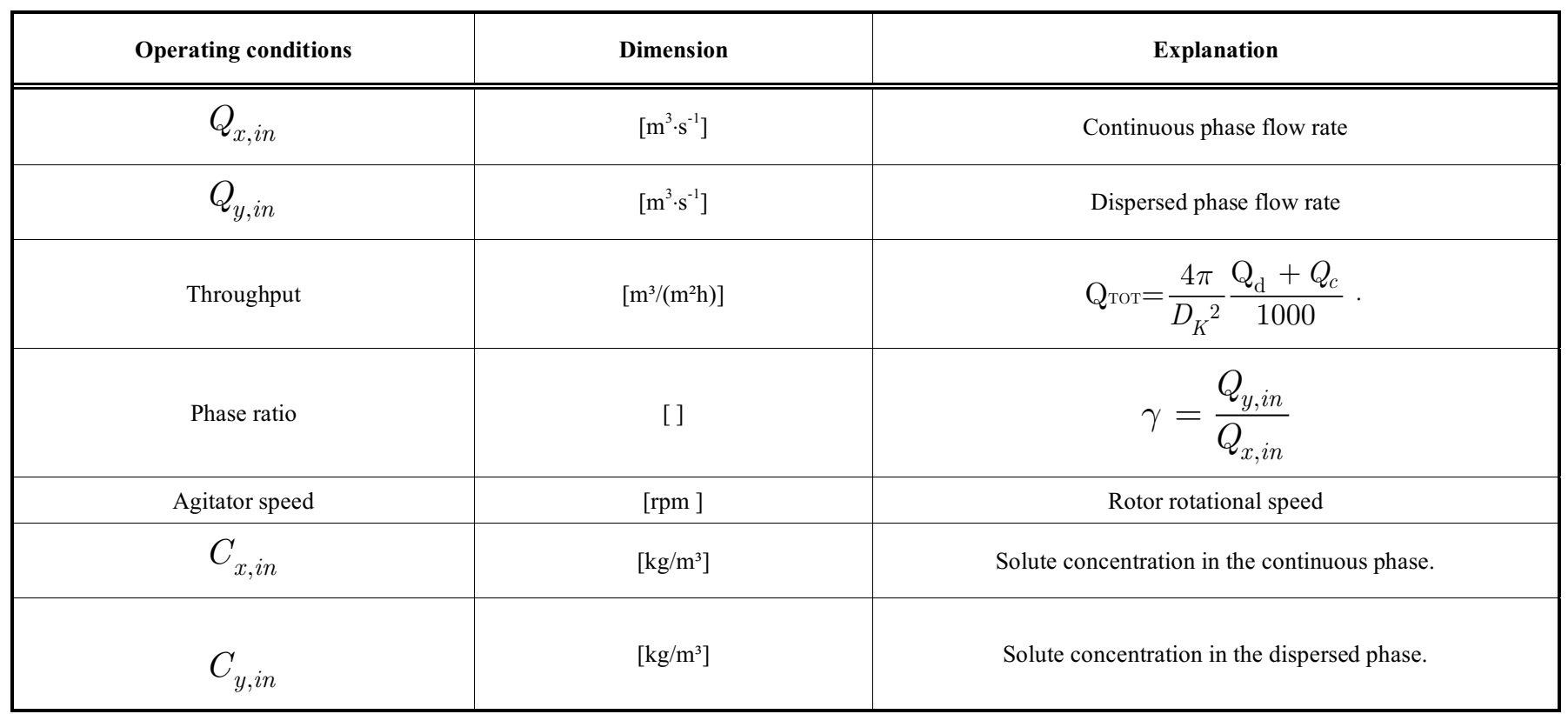

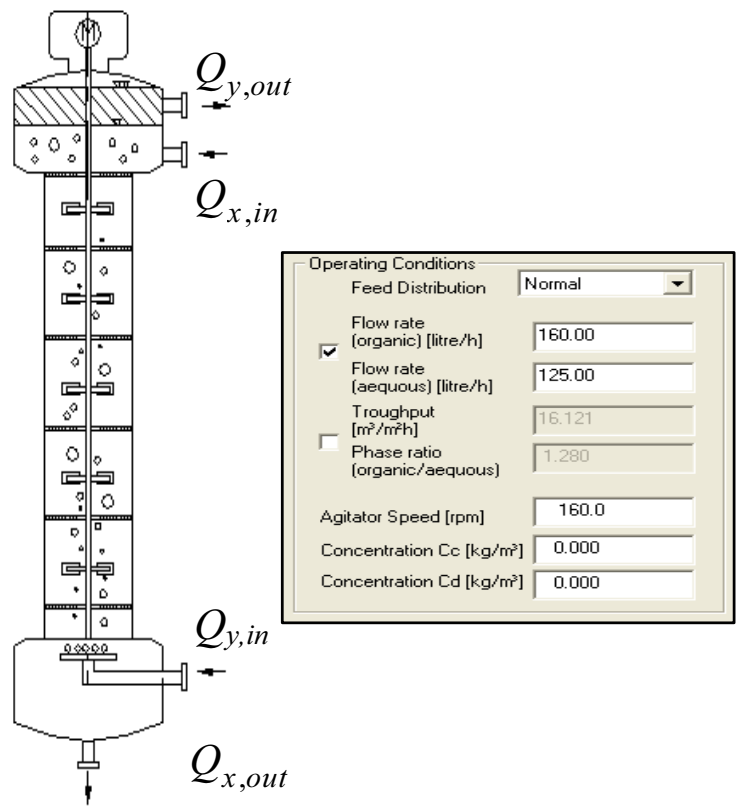

Fig. (A24). Input dialog for the column input variables.

Table A9. LLECMOD Output Files

\begin{tabular}{|c|c|}
\hline MatPropFile.txt & Concentration dependent chemical properties along the column height \\
\hline HoldupSs 1.txt & $\begin{array}{l}\text { Hold up, Sauter mean diameter, number distribution, solute concentration in the continuous and dispersed phases } \\
\text { along the column height. }\end{array}$ \\
\hline OutPutPath.txt & Listing of the output path, directory and file-names \\
\hline ColumnDimensions.txt & Contains the column geometry \\
\hline
\end{tabular}


The Compaq Array Visualizer is a program distributed with Compaq Digital FORTRAN. A sample of the MATLAB plots showing the steady state and transient responses is shown in Fig. (A26, a, b, c, d, e). Note that for writing the output files in a specified folder, the path of the directory must be defined as given in Fig. (A25). A short description of the output files is given in Table A9.

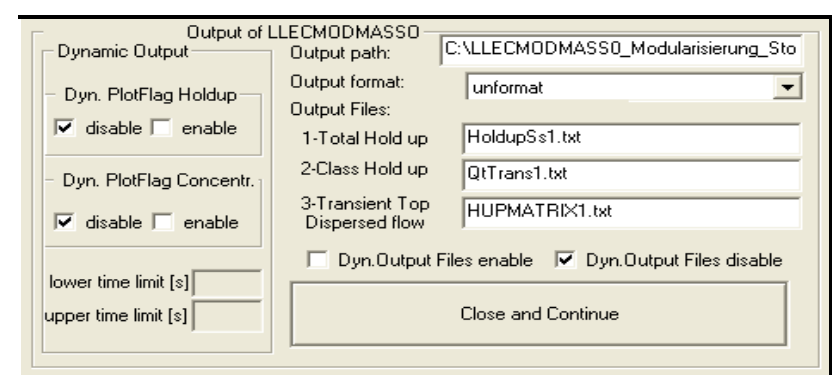

Fig. (A25). Output dialog for the simulation results.

In addition, some extra files can be generated containing the time dependent transient column behaviour. In detail, the concentration and hold-up profiles and all significant operation properties can be recorded dynamically. This functionality can be enabled by selecting the option Dynamic output in LLECMOD main dialog. The simulation results are plotted continuously with the Compaq Array Visualizer limited by an upper and lower time domain. The resulting transient files can be evaluated with Excel or MATLAB if Dyn. Output Files enable was activated.

\section{COALESCENCE PARAMETERS ESTIMATION PAC- KAGE}

Droplet coalescence is sensitive to hydrodynamics, physical-chemical properties, interfacial dynamics and mass transfer. Currently, there is no general correlation to predict the coalescence rate. However, basic experiments in a Venturi-tube have shown that the coalescence probability of droplets strongly depends on the droplet size, the hold-up and system properties [68-70].

Therefore, it is not possible to introduce a correlation for predicting the droplet coalescence independent of solving the population balance equation describing this phenomenon. This is because droplet coalescence is more complex than droplet breakage, which is related to the turbulent structure of the continuous phase.

The physicochemical properties of the continuous phase and the turbulent fluctuations play an important role in droplet coalescence. It is believed that droplet coalescence occurs if the contact time between any two randomly coalescing droplets exceeds the time required for the complete intervening film drainage and rupture. Coulaloglou and Tavlarides [11] expressed the coalescence frequency as a product of collision rate and coalescence efficiency based on the kinetic theory of gases and obtained the following expression:

$$
\begin{aligned}
& \omega\left(d, d^{\prime}, \phi_{y}, \boldsymbol{P}\right)=c_{3} \frac{\varepsilon^{1 / 3}}{1+\phi}\left(d+d^{\prime}\right)^{2}\left(d^{2 / 3}+d^{12 / 3}\right)^{1 / 2} \\
& \times \exp \left(-\frac{c_{4} \mu_{x} \rho_{x} \varepsilon}{\sigma^{2}(1+\phi)^{3}}\left(\frac{d . d^{\prime}}{d+d^{\prime}}\right)^{4}\right)
\end{aligned}
$$
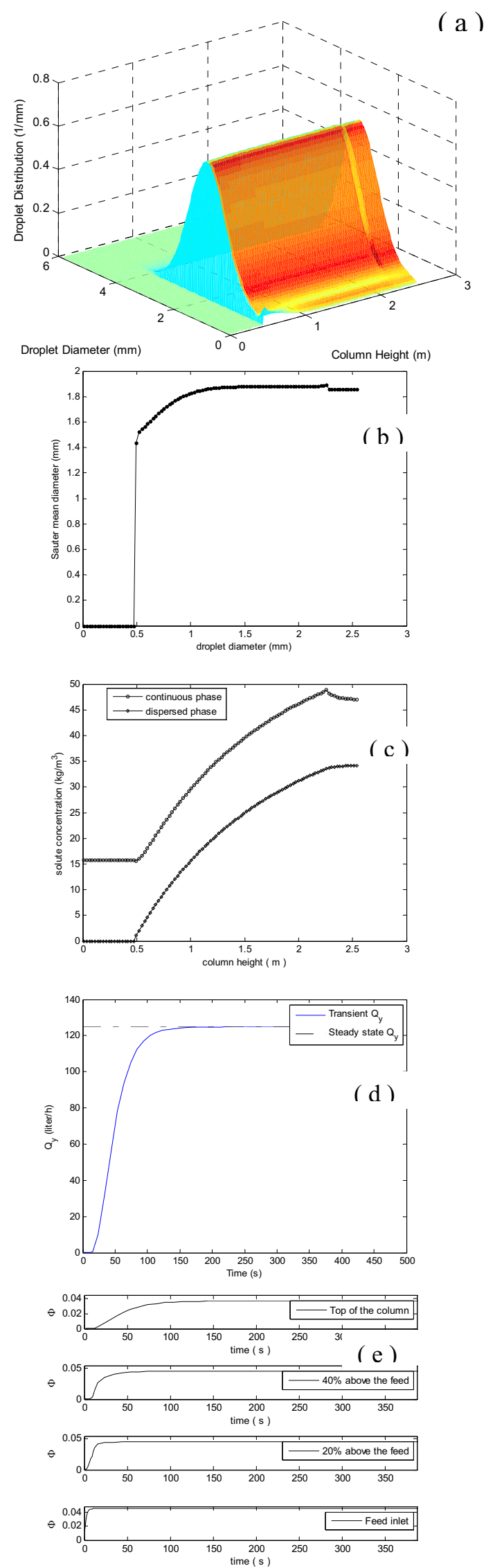

Fig. (A26):(a) Droplet volume density (b): Sauter mean diameter, (c) solute concentration profiles, (d): dispersed phase flow rate response, (e): dispersed phase hold up response along the column. 
To determine the unknown constants: $C_{3}$ and $C_{4}$ the droplet coalescence was investigated experimentally in a small laboratory-scale device, which is an RDC segment consisting of five compartments similar to the geometry given in Table 3 and having a diameter of $0.15 \mathrm{~m}$.

Droplet size distributions were measured at the inlet and the outlet of the segment. The phase flow rates were set in a range between 13.9 and 27.8150 to $300 \mathrm{rpm}$. To estimate $C_{3}$ and $C_{4}$, an integrated optimization package was developed to solve this inverse problem based on the present mathematical model that is simplified (by neglecting the axial dispersion) for this small scale device. The program estimates the unknown coalescence constants by specifying a coalescence model. These constants are obtained by an inverse solution of the PBE through minimizing the sum of squares of errors according to the following objective function:

$\chi^{2}(\boldsymbol{c})=[\boldsymbol{F}-\tilde{\boldsymbol{F}}(\boldsymbol{c})]^{T}[\boldsymbol{F}-\tilde{\boldsymbol{F}}(\boldsymbol{c})]$

where $c$ is the unknown coalescence constants vector (e.g. $\left.\boldsymbol{c}=\left[\begin{array}{ll}c_{1} & c_{2}\end{array}\right]\right)$. Therefore, the simulated steady state outlet cumulative distribution $\tilde{\boldsymbol{F}}$ is fitted to the experimental one, $\boldsymbol{F}$, by varying the coalescence parameters vector $\boldsymbol{c}$. This procedure is carried out using the Rosenbrock method (see Raman [71]), which uses only the function values and utilizes simple bounds on the estimated constants. Moreover, the optimisation algorithm is reinforced by a multivariate statistical tool to estimate the confidence intervals for the calculated constants. The performance of the Rosenbrock algorithm was also tested against the standard IMSL subroutine DBCPOL based on the direct search complex algorithm (see Fortran Subroutines [72]).

\section{REFERENCES}

[1] T.C Lo, M.H.I. Baird, C. Hanson (Eds): Handbook of Solvent Extraction, J. Wiley \& Sons, New York, 1983.

[2] J.C. Godfrey, M.J. Slater (Eds.): Liquid-Liquid Extraction Equipment. Chichester, J. Wiley \& Sons, 1994.

[3] H. Hulburt, S. Katz, "Some problems in particle technology. A statistical mechanical formulation", Chem. Eng. Sci., vol. 19, pp. 555-574, 1964.

[4] K.J. Valentas, A.R. Amundson, "Breakage and coalescence in dispersed phase systems", Ind. Eng. Chem. Fundam., vol. 5, pp. 533-542, 1966.

[5] S. Motz, A. Mitrovic, and E.-D. Gilles, "Comparison of numerical methods for the simulation of dispersed phase systems", Chem. Eng. Sci., vol. 57, pp. 4329-4344, 2002.

[6] F. Puel, G. Fevotte, and J.P. Klein, "Simulation and analysis of industrial crystallization processes through multidimensional population balance equations". Part 1: a resolution algorithm based on the method of classes, Chem. Eng. Sci., vol. 58, pp. 3715-3727, 2003.

[7] F.B Campos, P.L.C. Lage, "A numerical method for solving the transient multidimensional population balance equation using Euler-Lagrange formulation", Chem. Eng. Sci., vol. 58, pp. 27252744,2003

[8] G. Modes, H.-J. Bart, D. Rodrigues-Perancho, and D. Bröder, "Simulation of the fluid dynamics of solvent extraction columns from single droplet parameters", Chem. Eng. Tech., vol. 22 (3), pp. 231-236, 1999.
[9] G. Casamatta, A. Vogelpohl, "Modelling of fluid dynamics and mass transfer in extraction columns", Ger. Chem. Eng., vol. 8, pp. 96-103, 1985.

[10] A. Gerstlauer, „Herleitung und Reduktion populationsdynamischer Modelle am Beispiel der Fluessig-Fluessig-Extraktion“, FortschrittBerichte VDI Reihe, 3, Verfahrenstechnik, Nr. 612, Düsseldorf, VDI-Verlag, 1999.

[11] C.A. Coulaloglou, L.L. Tavlarides, "Description of interaction processes in agitated liquid-liquid dispersions". Chem. Eng. Sci., vol. 32, pp. 1289-1297, 1977.

[12] E. Chatzi, J.M. Lee, "Analysis of interactions for liquid-liquid dispersions in agitated vessels", Ind. Eng. Chem. Res., vol. 26, pp. 2263-2267, 1987.

[13] Alatiqi, G. Aly, F. Mjalli, and C.J. Mumford, "Mathematical modeling and steady-state analysis of a Scheibel extraction column", Can. J. Chem. Eng., vol. 73, pp. 523-533, 1995.

[14] O. Weinstein, R. Semiat, and D.R. Lewin, "Modelling, simulation and control of liquid-liquid extraction columns", Chem. Eng. Sci., vol. 53, pp. 325-339, 1998.

[15] F.S. Mjalli, "Neural network model-based predictive control of liquid-liquid extraction contactors", Chem. Eng. Sci. vol. 60, pp. 239-253, 2005

[16] S.D. Al Khani, C. Gourdon, G. Casamatta, "Simulation of hydrodynamics and mass transfer of disks and rings pulsed column", Ind. Eng. Chem. Res., vol. 27, pp. 329-333, 1988.

[17] C. Tsouris, V.I. Kirou, and L.L. Tavlarides, "Drop size distribution and holdup profiles in a multistage extraction column", AIChE J., vol. 40, pp. 407-418, 1994.

[18] V. Alopaeus, J. Koskinen, K.I. Keskinen, and J. Majander, "Simulation of the population balances for liquid-liquid systems in a nonideal stirred tank: Part 2- parameter fitting and the use of multiblock model for dense dispersions", Chem. Eng. Sci., vol. 57, pp. $1815-1825,2002$.

[19] M.M. Attarakih, H.-J. Bart, and N.M. Faqir, "Numerical solution of the spatially distributed population balance equation describing the hydrodynamics of interacting liquid-liquid dispersions", Chem. Eng. Sci., vol. 59, pp. 2567-2592, 2004.

[20] M.M. Attarakih, H.-J. Bart, and N.M. Faqir, "Numerical Solution of the Bivariate Population Balanced Equation for the Interacting Hydrodynamics and Mass Transfer in Liquid-Liquid Extraction Columns". Chem. Eng. Sci., vol. 61, pp. 113-123, 2006.

[21] L. Steiner, M. Bamelli, and S. Hartland, "Simulation of hydrodynamic performance of stirred extraction column", AIChE J., vol. 45, pp. 257-267, 1999

[22] S.E. Kentish, G.W. Stevens, and H.R.C. Pratt, "Estimation of coalescence and breakage rate constants within a Kühni column", Ind. Eng. Chem. Res., vol. 37, pp. 1099-1106, 1998.

[23] S.D. Al Khani, C. Gourdon, and G. Casamatta, "Dynamic and steady-state simulation of hydrodynamics and mass transfer in liquid-liquid extraction column", Chem. Eng. Sci., vol. 44, pp. 1295$1305,1989$.

[24] M. Cabassud, C. Gourdon, and G. Casamatta, "Single drop breakup in a Kühni column”, Chem. Eng. J., vol. 44, pp. 27-41, 1990.

[25] S. Mohanty, "Modeling of liquid-liquid extraction column: A review", Rev. Chem. Eng., vol. 16, pp. 199-248, 2000.

[26] S.A. Schmidt, „Populationsdynamische Simulation gerührter Extraktionskolonnen auf Basis von Einzeltropfen- und Tropfenschwarmuntersuchungen"; Dissertation, TU Kaiserslautern, Germany, 2005.

[27] T. Steinmetz, "Tropfenpopulationsbilanzgestütztes Auslaugungsverfahren zur Skalierung einer gerührten Miniplant-Extraktionskolonne“, Dissertation, TU Kaiserslautern, Germany, 2007.

[28] M.M. Attarakih, "Solution Methodologies for the Population Balance Equations Describing the Hydrodynamics of Liquid-Liquid Extraction Contactors", Dissertation, TU Kaiserslautern, Germany, 2004.

[29] M.M. Attarakih, H.-J. Bart, and N.M. Faqir, "Solution of the droplet breakage equation for interacting liquid-liquid dispersions: a 
conservative discretization approach", Chem. Eng. Sci., vol. 59, pp. 2547-2565, 2004b.

[30] M.M. Attarakih, H.-J. Bart, and N.M. Faqir, "A Hybrid Scheme for the Solution of the Bivariate Spatially Distributed Population Balanced Equation", Chem. Eng. Tech., Vol. 29, pp. 435-441, 2006b.

[31] M.M. Attarakih, H.-J. Bart, and N.M. Faqir, "LLECMOD: A windows-based program for hydrodynamics simulation of liquid-liquid extraction columns", Chem. Eng. Sci., vol. 45, pp. 113-123, $2006 \mathrm{c}$.

[32] T. Steinmetz, S.A. Schmidt, and H.-J. Bart, ,Modellierung gerührter Extraktionskolonnen mit dem Tropfenpopulationsbilanzmodell“, Chem. Ing. Tech., vol. 77(6), pp. 723-733, 2005.

[33] C. Gourdon, G. Casamatta, and G. Muratet, "Population balance based modeling of solvent extraction columns", in: Godfrey, J. C. Slater, M.J. (Eds.), Liquid-liquid extraction equipment, John Wiley \& Sons, New York, pp. 137-226, 1994.

[34] A. Kumar, S. Hartland, "Correlations for prediction of mass transfer coefficients in single drop systems and liquid-liquid extraction columns", Trans. Inst. Chem. Eng. vol. 77 (Part A), pp. 372-384, 1999.

[35] A.B. Newman, "The drying of porous solids: Diffusion and surface emission equations", AIChE J., vol. 27, pp. 203.220, 1931.

[36] A.E. Handlos, T. Baron, "Mass transfer from drops in liquid extraction”, AIChE J., vol. 3, pp. 127-136, 1957.

[37] R. Kronig, J. Brink, "On the theory of extraction from falling droplets”, Appl. Sci. Res., A2, pp. 142-154, 1950.

[38] B.H. Wolschner, ,Konzentrationsprofile in Drehscheibenextraktoren“, Dissertation, Technische Universität, Graz, Austria, 1980.

[39] W.J. Koschinsky, C.H. Young, "Modeling drop-side mass transfer in agitated poly-dispersed liquid-liquid systems", Chem. Eng. Sci., vol. 40, pp. 2355-2361, 1989.

[40] M.J. Slater, "A Combined Model of Mass Transfer Coefficients for Contaminated Drop Liquid-Liquid Systems", Can. J. Chem. Eng., vol. 73, pp. 462-469, 1995.

[41] H.-J. Bart, Reactive Extraction, Berlin, Springer, 2001.

[42] R. McGraw, "Description of aerosol dynamics by the quadrature method of moments", Aerosol Sci. Tech., vol. 27: pp. 255-265, (1997).

[43] N.P. Wilburn, "Mathematical determination of concentration profiles in two-phase continuous countercurrent extractors", Ind. Eng. Chem. Fundam., vol. 3, pp. 189-195, 1964.

[44] A. Kurganov, E. Tadmor, "New high-resolution central schemes for nonlinear conservation laws and convective diffusion equations", J.Comput. Phys., vol. 160, pp. 241-282, 2000.

[45] A.J. Klee, R.E. Treybal, 2Rate of rise or fall of liquid drops", AIChE J., vol. 2, pp. 444-447, 1956.

[46] A. Vignes, "Hydrodynamique des dispersions", Genie Chimique, vol. 93, pp. 129-142, 1965.

[47] J.R. Grace, T. Wairegi, and T.H. Nguyen, "Shapes and velocities of single drops and bubbles moving freely through immiscible liquids", Trans. Inst. Chem. Eng., vol. 54, pp. 167-173, 1976.

[48] J.A. Wesselingh, A.M. Bollen, "Single particles, bubbles and drops: Their velocities and mass transfer coefficients", Trans. Inst. Chem. Eng., vol. 77, pp. 89-96, 1999.

[49] M. Henschke, "Auslegung pulsierter Siebboden-Extraktionskolonnen", Habilitationsschrift, RWTH Aachen, Aachen, Germany, 2003.

[50] J.C. Godfrey, M.J. Slater, "Slip velocity relationships for liquidliquid extraction columns", Trans. I ChemE, vol. 69, pp. 130-141, 1991.

[51] H. Sovova, "Breakage and Coalescence of drops in a batch stirred vessel - II. Comparison of model and experiments", Chem. Eng. Sci., vol. 36, pp. 1567-1573, 1981.

[52] M. Laso, L. Steiner, and S. Hartland, "Dynamic simulation of agitated liquid-liquid dispersions - II. Experimental determination of breakage and coalescence rates in a stirred tank", Chem. Eng. Sci., vol. 42, pp. 2437-2445, 1987.

[53] G. Narsimhan, D. Ramkrishna, "Analysis of drop size distributions in liquid-liquid dispersions", AIChE J., vol. 26, pp. 991-1000, 1980.
[54] S.A. Schmidt, M. Simon, M.M. Attarakih, L. Lagar, and H.-J. Bart, "Droplet population balance modeling - hydrodynamics and mass transfer”, Chem. Eng. Sci., vol. 61, pp. 246-256, 2006.

[55] T. Misek, "General Hydrodynamic Design Basis for Columns, in Liquid-Liquid Extraction Equipment", (Eds.) J.C. Godfrey and M.J. Slater, John Wiley \& Sons: Chichester, pp. 95-113, 1994.

[56] H. Hufnagl, M. McIntyre, and E. Blass, "Dynamic behaviour and simulation of a liquid-liquid extraction column", Chem. Eng. Tech., vol. 14, pp. 301-306, 1991.

[57] G. Casamatta, "Comportement de la population des gouttes dans une colonne d'extraction: Transport, rupture, coalescence, transfer de matiere", Dissertation, Institut National Polytechnique de Toulouse, France, 1981.

[58] T. Kronberger, A. Ortner, W. Zulehner, and H.-J. Bart, Numerical Determination of Droplet Size in Extraction Columns, in: 7th European Conference on Mathematics in Industry (Ed: A. Fasano, M. Primerico), Teubner Stuttgart, pp. 247-254, 1994.

[59] A. Kumar, S. Hartland, Empirical prediction of operating variables. Liquid-liquid extraction equipment. J.C. Godfrey and M.J. Slater. Chichester, John Wiley \& Sons, pp. 141-226, 1994.

[60] R. Bauer, „Die Längsvermischung beider Phasen in einer gerührten Fest-Flüssig-Extraktionskolonne“, Dissertation, ETH Zürich, Switzerland, 1976.

[61] E. Sommeregger, B. Wolscher, and R. Marr, "Calculation of the concentration profile in a rotating disc contactor", MS 782/80, Chem. Ing. Tech., vol. 52, pp. 277, 1980.

[62] G. Modes, „Grundsätzliche Studie zur Populationsdynamik einer Extraktionskolonne auf Basis von Einzeltropfenuntersuchungen“, Dissertation, Universität Kaiserslautern, Germany, 2000.

[63] M.A. Hsia, L.L. Tavlarides, "A simulation model for homogeneous dispersion in stirred tanks", Chem. Eng. J., vol. 20, pp. 225-236, 1980.

[64] C. Tsouris, L.L. Tavlarides, "Control of dispersed-phase volume fraction in multistage extraction columns", Chem. Eng. Sci., vol. 46, pp. 2857-2865, 1990.

[65] V. Alopaeus, J. Koskinen, and K.I. Keskinen, "Simulation of population balances for liquid-liquid systems in a non-ideal stirred tank. Part1: description and qualitative validation of model", Chem. Eng. Sci., vol. 5, pp. 5887-5899, 1999.

[66] S.L. Ross, F.H. Verhoff, and R.C. Curl, "Droplet Breakage and Coalescence Processes in an Agitated Dispersion. 2. Measurement and Interpretation of Mixing Experiments", Ind. Eng. Chem. Fundam., vol. 17(2), pp. 101-108, 1978.

[67] P.M. Bapat, L.L. Tavlarides, "Mass transfer in liquid-liquid CFSTR", AIChE J., vol. 31(4), pp. 659-666, 1985.

[68] M. Simon, H.-J. Bart, "Exp. Studies of Coalescence in Liq./Liq.Systems", Chem. Eng. Tech., vol. 25, pp. 481-484, 2002.

[69] M. Simon, S.A. Schmidt, and H.-J. Bart, "The droplet population balance model-Estimation of breakage and coalescence", Chem. Eng. Tech., vol. 26, pp. 745-750, 2003.

[70] M. Simon, „Koaleszenz von Tropfen und Tropfenschwärmen“, Dissertation, TU Kaiserslautern, Germany, 2004.

[71] R. Raman, Chemical Process Computations, Elsevier Applied Science Publishers Ltd., New York, 1985.

[72] Fortran Subroutines for Mathematical Applications, Visual Numerics Inc., Stuttgart, 1997.

[73] L. Steiner, S. Hartland, „Neues zur mathematischen Modellierung von Flüssig-Flüssig-Extraktionskolonnen“, Chem. Ing. Tech., vol. 55(3), pp. 94-201, 1983

[74] V. Cauwenberg, J. Degreve, and M.J. Slater, "The Interaction of Solute Transfer, Contaminants and Drop Break-Up in Rotating Disc Contactors: Part I. Correlation of Drop Breakage Probabilities", Can. J. Chem. Eng., vol. 75, pp. 1046-1055, 1997.

[75] G. Garthe, "Fluid Dynamics and Mass Transfer of Single Particles and Swarms of Particles in Extraction Column", Dissertation, TU München, Germany, 2006.

[76] G. Zamponi, J. Stichlmair, A. Gerstlauer, and E.-E. Gilles, "Simulation of the transient behaviour of a stirred liquid/liquid extraction column", Comp. Chem. Eng., vol. 20, pp. 963-968, 1996. 
[77] T. Misek, R. Berger, and J. Schröter, European Federation of Chemical Engineering: Standard test systems for liquid extraction. $2^{\text {nd }}$ Edition. The Institution of Chemical Engineers, Warwickshire, England, 1985, (s.: http://dechema.de/extraktion).

[78] D. Ramkrishna, "Population Balances: Theory and applications to particulate systems in engineering", Academic Press, San Diego, 2000.

[79] A.H. Skelland, R.M. Wellek, "Resistance to mass transfer inside droplets", AIChE J. , vol 10(4), pp. 491-496, 1964.

[80] A.E. Handlos, T. Baron, "Mass and Heat Transfer from Drops in Liquid-Liquid Extraction”, AIChE J., vol. 3(1), pp. 127-135, 1957.

[81] T. Pilhofer, D. Mewes, Weinheim: VCH, 1979.

[82] G.S. Laddha, T.E. Degaleesan, Transport phenomena in liquid extraction: Tata McGraw Hill, New Delhi, 1976.
[83] F.H. Garner, M. Tayeban, „The importance of the wake in mass transfer form both continuous and dispersed phase systems", Ann. Real. Soc. Espan. Fis. Y Quim., vol 56b, pp. 479, 1960.

[84] R.R. Treybal, Liquid Extraction, New York: McGraw Hill, 1963.

[85] R. Clift, J.R. Grace, M.E. Weber, Bubbles, drops and particles, New York: Academic Press, 1978.

[86] P.M. Heertjes, W.A. Holve, and H. Talsma, "Mass transfer between isobutanol and water in a spray column", Chem. Eng. Sci., vol. 3, pp. 122-142, 1954.

[87] J.M. Slater, Rate coefficients in liquid-liquid extraction studies. In: Godfrey, J.C., Slater, J.M. (Hrsg.), Liquid-Liquid Extraction Equipment, John Wiley \& Sons, Chichester, 1994. 